\title{
EL ESPACIO PERCIBIDO Y CONCEBIDO DEL QUICENTRO SHOPPING CENTER EN DOS ESCALAS DE LA CIUDAD DE QUITO
}

\author{
Daniela Sofía Loaiza Jiménez \\ Universidad del Bío Bío - Doctorado en Arquitectura y Urbanismo \\ Concepción - Chile - CP. 4081112 \\ Director de tesis: PhD. Aarón Napadensky Pastene \\ Co-director de tesis: PhD. Joaquín Sabaté Bel \\ Colaboración: Carlos Luis Rangles Álvarez \\ loaizadaniela@gmail.com
}

\section{RESUMEN}

En la narrativa académica acerca de los Shopping centers existen debates y discusiones acerca de la jerarquización espacial y transformaciones urbanísticas, en diferentes escalas, producidas en torno a estas arquitecturas. Por un lado existe una aproximación "apocalíptica" que la acusa de ser una amenaza para la ciudad. Por otro lado existe una aproximación que plantea al Shopping center como una oportunidad para transformar y dinamizar el espacio urbano y, por último, existe una aproximación más contemporánea que describe al shopping center como un elemento y un fenómeno que ha provocado transformaciones morfológicas, ha reordenado los usos en la ciudad. Así, en la presente investigación se discuten estas diferentes aproximaciones a partir del estudio de caso Quicentro Shopping center en la ciudad de Quito Ecuador, analizando el espacio concebido (planificado) y el espacio percibido (construido) en la escala de la ciudad y en la escala del sector donde está insertado. Así, ésta investigación busca comprender el rol que desempeña el shopping center en la ciudad de Quito en diferentes escalas desde su planificación y su efectiva materialización.

Palabras clave: shopping center, espacio concebido, espacio percibido, transformaciones urbanísticas.

\begin{abstract}
In the current academic narrative about shopping mall debates and discussions exists in regards of the spatial hierarchy and the urban transformations, in different scales, produced around these architectures. On the one hand there is an "apocalyptic" approach that accuses the mall as a threat to the city. On the other hand the other approach poses the shopping mall as an opportunity to transform and invigorate the urban space. Finally there is a contemporary approach that describes the shopping mall as an element and a phenomenon that has triggered morphological transformations. It has rearranged the uses in the city. Thus in this present research all these different approaches are discussed from the Quicentro Shopping mall case study located in Quito - Ecuador. This by analyzing the conceived space (Planned) and the perceived space (Built) in a city size scale as a general and a sector scale around the area where the mall is inserted. Thus this research seeks to understand the role played by the Shopping mall in Quito and the different scales since its planning to its effective materialization.
\end{abstract}

Key-words: shopping center, conceived space, perceived space, urban transformations 


\section{INTRODUCCIÓN}

El surgimiento del shopping center a mediados del siglo XX, su proliferación y expansión como una nueva tipología arquitectónica y urbanística (Bell, 2006) de gran almacén, ha colonizado tanto los centros tradicionales como los suburbios y ciudades satélites residenciales bajo el discurso de renovar la vida colectiva, la sociabilidad de la ciudad industrial y de ser un nuevo envolvente de la vida urbana (Lipovetsky, 2006, 2007).

Es importante resaltar, que en este contexto, el pensamiento neoliberal lideraba el momento político a nivel global, precedido por un momento de recesión económica que desarrolló un cierto desagrado por la "falta de libertad" y desató nuevas leyes de consumo (Hall, 1996). Así, en este período, el shopping center remplaza a los proyectos de planificación urbanística pública y modifica las lógicas de producción de la ciudad.

La dialéctica entre la esta arquitectura de gran almacén y las prácticas sociales, culturales, políticas, económicas y tecnológicas de la vida urbanística contemporánea ahí contenidas, se han venido manifestando espacialmente en las ciudades contemporáneas, las cuales, al mismo tiempo modifican los comportamientos, las prácticas cotidianas y necesidades sociales (Choay, 1997).

Bell (2006), describe a la cultura emergente de la sociedad posindustrial como una cultura que provoca una desenfrenada proliferación de sus demandas y satisfacción de sus necesidades, deseos y derechos que son, finalmente, manifestados y espacializados en las ciudades puesto que es una cultura donde la producción y la distribución estructuran las jerarquías económicas y espaciales.

Es decir, las efectivas necesidades de la sociedad se han venido materializando (Habermas, 2006) y han provocado transformaciones en la forma y el reordenamiento de usos de las ciudades contemporáneas. En consecuencia, el shopping center se origina como una respuesta a esta cultura emergente de la sociedad posindustrial, y se convierte en un nuevo elemento urbanístico que transforma y que es transformado a la velocidad de las necesidades sociales en un momento determinado. Así, mientras en el período de posguerra los centros tradicionales de las ciudades pierden su jerarquía en la estructura espacial de las ciudades, los shopping centers se convierten en los nuevos espacios que estructuraban la vida colectiva de las periferias norteamericanas (Bell, 2006). En este sentido el shopping center se volvió en una manifestación o materialización del pensamiento neoliberal.

El shopping center ha evidenciado una importante transición de una época donde la producción, como actividad fundamental de la ciudad, ha sido relevada por una época de consumo, provocada por una producción masiva de la industria del retail. Esta producción en masa ha remplazado al comercio artesanal o desindustrializado y se ha constituido como elemento esencial de la vida cotidiana en las ciudades, imponiéndose como base estructural de la vida pública (Lipovetsky, 2007) y configurando un nuevo estilo de vida vinculado al consumo, al ocio y al entretenimiento en las periferias suburbanas dispersas y fragmentadas.

En un primer momento, el shopping center fue concebido como un espacio de encuentro colectivo en las extendidas periferias residenciales norteamericanas, abastecidas por sistemas de carreteras que facilitaron la masificación del automóvil individual como el principal medio de transporte (Bell, 2006). Así, mientras los shopping centers se convierten en los nuevos espacios que estructuraban la vida colectiva de las periferias norteamericanas (Bell, 2006) en el período de posguerra los centros tradicionales de las ciudades empiezan a perder su jerarquía en la estructura espacial de las ciudades.

En este sentido el shopping center se convirtió en la manifestación espacial de las lógicas del mercado, y por consiguiente, los grandes operadores privados eran los encargados de la construcción y producción de la ciudad (Dupuy, 1998), asignando el valor del suelo, su uso, su forma de ocupación, su densificación y su accesibilidad.

Es importante resaltar, que en este contexto, el pensamiento neoliberal lideraba el momento político a nivel global, precedido por un momento de recesión económica que desarrolló un cierto desagrado por la "falta de libertad" y desató nuevas leyes de consumo (Hall, 1996). Así, en este período, el shopping center remplaza a los proyectos de planificación urbanística pública y modifica las lógicas de producción de la ciudad.

El shopping center ha sido tanto hecho como fenómeno, causa y consecuencia de las transformaciones en las formas de consumo del mercado y del territorio. Tal como lo describen varios autores (Castells, 2004; 
Habermas, 2006; Rossi, 2007; Venturi, 2008) la dimensión espacial es la materialización de los cambios sociales de un momento determinado. Así, la dialéctica entre la esta arquitectura de gran almacén y las prácticas sociales, culturales, políticas, económicas y tecnológicas de la vida urbanística contemporánea ahí contenidas, se han venido manifestando espacialmente en las ciudades contemporáneas, las cuales, al mismo tiempo modifican los comportamientos, las prácticas cotidianas y necesidades sociales (Choay, 1997).

Según publicaciones del International Council of Shopping Centers (2015) existen 1,555 Shopping Centers en Argentina, Brasil, Chile, Colombia, México y Perú. Este número incrementará a 2387, con base en análisis de estadísticas de proyección, hasta el año de 2015. En estos 6 países está distribuido el $87 \%$ de los Shopping Centers de América Latina, con un total de 1800 Shopping Centers. De estos países, Chile es el país que tiene el porcentaje más alto de Shopping Centers, con 22.2 metros cuadrados por cada 100 habitantes (y con el porcentaje de ingreso per cápita más alto: 20,072 dólares anual), México el segundo con 16.9 metros cuadrados por cada 100 habitantes, Colombia con 10.8 metros cuadrados por cada 100 habitantes. Perú con 9.2, Brasil con 7.8 y Argentina con 5.4 por cada 100 habitantes.

En la narrativa académica acerca de los Shopping Centers, existen debates sobre las transformaciones urbanísticas, en diferentes escalas, producidas en torno a estas arquitecturas. Por un lado existe la corriente que "sataniza" al shopping center, acusándolo de aniquilar las dinámicas de espacio público, introduciéndolas dentro de un solo objeto que niega la ciudad. Se presenta a esta arquitectura como un objeto genérico demoledor de cascos urbanos, como el responsable del desparrame urbano (urban sprawl), como un espacio artificial que transforma todo en mercancía e incentiva a la pérdida de valores sociales transformando a las personas en objetos

Por otro lado existe una corriente que plantea al shopping center como arquitectura que produce un impacto positivo en la renovación y transformación del espacio urbano contemporáneo y fortalece las dinámicas en el espacio público y facilita la sociabilidad. Además, lo presenta como una tipología comercial que evoluciona a la velocidad de las necesidades de la gente, por lo tanto es abierto a la transformación, tanto programática como morfológica, y facilitan la transposición de actividades e incentivan a la diversidad de usos, usuarios y horarios.

Y una tercera corriente más contemporánea y científica, que sin tener una postura "a favor" o "en contra", describe al shopping center como un fenómeno que ha evolucionado y se ha transformado (retomando conceptos de la primera concepción del shopping center) para transformar a su vez la morfología de la ciudad, sus dinámicas y reordenar sus usos y a su vez, la ciudad lo transforma a él. Estas tres corrientes serán presentadas el tercer título de éste artículo, a manera de marco teórico

En el cuarto título se presenta el estudio de caso, el Quicentro Shopping Center (QSC) en la ciudad de Quito, realizando un análisis en la escala de la ciudad desde el espacio concebido (planificación de la ciudad) y desde el espacio percibido (construido) en diferentes años, antes, durante y después de la inserción del QSC. Las variables a ser analizadas son: uso de suelo, densidad de población, movilidad y transporte. A continuación, se desarrolla el análisis del QSC en la escala del sector, cuyo recorte espacial es la parcela original de donde está, actualmente, insertado el shopping center. Este análisis es realizado desde el espacio concebido y percibido en diferentes años, antes, durante y después de la inserción del QSC. Las variables analizadas son: uso de suelo, densidad de población, movilidad y transporte y zonificación/edificabilidad.

Para terminar éste artículo se concluye con las consideraciones finales donde se encuentran, también, algunos comentarios, cuestionamientos y sugerencias que puedan aportar al desarrollo de futuras investigaciones.

\section{OBJETIVOS, METODOLOGÍA Y RESULTADOS ESPERADOS}

El shopping center, al ser una arquitectura que ha proliferado por todo el globo y ha sido asociada con el debilitamiento del rol del espacio público en las ciudades, con la globalización de la economía y la cultura, con la modificación de dinámicas urbanísticas y con el consumo de masas se considera importante estudiar las transformaciones morfológicas y el reordenamiento de usos para comprender el efectivo rol que desempeña el shopping center en la estructura espacial de las ciudades contemporáneas. En éste artículo será analizado el caso del Quicentro Shopping Center en la ciudad de Quito - Ecuador. 
El shopping center ha sido discutido desde tres aproximaciones; como amenaza, como oportunidad y como un detonante de dinámicas de ocupación y construcción del territorio. En éste artículo se realizará, en un primer momento, una disertación de éstas tres aproximaciones y, posteriormente, se realizarán un análisis de las tres ópticas desde el análisis del espacio concebido (planificado) y el espacio percibido (construido o materializado) de la ciudad de Quito en la escala de la ciudad y en la escala del sector de Iñaquito donde está insertado el Quicentro Shopping Center.

El Objetivo general de éste artículo es comprender si el Quicentro Shopping Center es una arquitectura que modifica la estructura espacial de la ciudad de Quito, transforma su forma urbana y reordena sus usos en diferentes escalas.

El objetivo general mencionado parte de una hipótesis general que sugiere que el shopping center es una arquitectura que modifica la forma de la ciudad y reordena sus usos con el paso del tiempo, desde su planificación (espacio concebido) y su materialización (espacio percibido/construido) en diferentes escalas.

Para responder a esta hipótesis general se han planteado dos objetivos específicos que responden a dos sub-hipótesis de la tesis:

El primer objetivo específico de este artículo es evidenciar los planteamientos de la planificación (concepción) de la ciudad de Quito en diferentes momentos (desde 1970 hasta 2015) en relación a la inserción de los shopping centers, más específicamente a la del QSC. Y la sub-hipótesis sugiere que los shopping re-direccionan la inversión privada y atraen recursos y flujos económicos que aseguran la inversión pública. Los shopping centers han sido concebidos como una nueva forma de hacer ciudad en diferentes escalas. Este análisis será realizado en diferentes escalas; ciudad y en escala del sector:

En la escala de la ciudad de Quito se analizará_la estructura espacial planificada a partir del cruce de capas de usos de suelo, transporte y densidad poblacional para identificar si el Quicentro Shopping center han redireccionado la inversión privada y pública, provocando transformaciones en la estructura espacial de la ciudad. En esta escala será realizado un análisis comparativo de la ciudad de Quito concebida, antes, durante y después de la inserción del Quicentro Shopping Center.

En la escala del Sector de Iñaquito se analizará, también, el uso de suelo, el transporte, la densidad poblacional propuestos por los planes de ordenamiento territorial, y adicionalmente la zonificación y edificabilidad para evidenciar la diversidad morfológica y de usos planificados. En esta escala se busca identificar la relación directa entre la inserción del Quicentro Shopping center y la planificación del Sector; transformaciones morfológicas y reordenamiento de usos, antes, durante y después de su construcción.

El segundo objetivo específico de éste artículo es evidenciar la efectiva construcción (percepción o materialización), transformaciones morfológicas y el reordenamiento de usos en la ciudad de Quito en diferentes períodos (desde 1970 hasta 2010), con relación a la inserción de los shopping centers, más específicamente a la del QSC. La sub-hipótesis sugiere que existe una estrecha relación entre la inserción de los shopping centers, las transformaciones morfológicas y el reordenamiento de usos en la ciudad de Quito. Los shopping centers, y más específicamente el Quicentro Shopping Center está vinculado con la forma en la que se ha construido la ciudad.

Éste análisis será realizado en la escala de la ciudad de Quito y en la escala del Sector de Iñaquito donde está insertado el Quicentro Shopping Center.

En escala de la ciudad de Quito se analizará la efectiva estructura espacial a partir del cruce de capas de usos de suelo, transporte y densidad poblacional para identificar la efectiva materialización y jerarquización del espacio urbano a partir de la inserción de los shoppings centers. En esta escala será realizado un análisis comparativo de la ciudad de Quito percibida (construida), antes, durante y después de la inserción del Quicentro Shopping Center.

En la escala del Sector de Iñaquito se analizará, también, el efectivo uso de suelo, el transporte, la densidad poblacional, y adicionalmente la zonificación y edificabilidad para evidenciar la diversidad morfológica y de usos materializados en el sector.. En esta escala se busca identificar la relación directa entre la inserción del Quicentro Shopping, las transformaciones morfológicas y reordenamiento de usos, antes, durante y después de su construcción. 
El análisis será realizado desde el enfoque de Henri Lefebvre (2008) en su libro La Producción del Espacio el cual fue, posteriormente, ampliado por Edward Soja (2008) en su escrito sobre el Tercer Espacio donde son descritos y conceptualizados los tres componentes del espacio social; el espacio CONCEBIDO (Lefebvre, 2008) o planificado, el espacio PERCIBIDO (Lefebvre, 2008) o físico-espacial, y el espacio VIVIDO (Lefebvre, 2008; Soja, 2008) o apropiado/experimentado.

Para Lefebvre (2008) el espacio social consta de tres sub-componentes del mismo espacio:

El espacio concebido, refiriéndose a una representación o expresión abstracta, simbólica e imaginaria de un espacio. A una primera noción o idea de lo que el espacio debe ser; un plan o un germen de proyecto.

El espacio percibido, definido como el espacio físico, material o tangible. Todo lo que los ojos alcanzan a ver y lo que se puede percibir a través de los sentidos.

El espacio vivido, que fue profundizado por Soja (2008) como un espacio donde lo concebido y lo percibido actúan simultáneamente e incorporan la experiencia del lugar, sus diferentes formas de apropiación, las diferentes maneras de volver suyo el espacio y ocuparlo.

Tal como fue enunciado anteriormente, en éste artículo el análisis se lo realizará solamente desde el espacio concebido y el espacio percibido, buscando comprender si el Quicentro Shopping Center es una arquitectura que modifica la forma de la ciudad, reordena sus usos y modifica la estructura espacial en diferentes escalas desde su planificación y su efectiva construcción. En los dos casos el estudio se realizará en el período desde 1970 hasta el 2015, con cortes cada diez años en los cinco primeros casos y quince en el último para observar gráficamente las transformaciones urbanas.

El material producido en esta investigación ha permitido generar cartografías y mapeos inéditos que en su conjunto permiten evidenciar la estrecha relación entre el shopping center, la planificación y la efectiva construcción.

\section{EL SHOPPING CENTER - TRES APROXIMACIONES}

\subsection{Amenaza}

En esta primera corriente, que se inicia desde mediados de la década de 1970 hasta inicios del año 2000 en Europa y Norteamérica, y en Latinoamérica llegan hasta finales del 2000, se presenta al Shopping center como la respuesta materializada a una política y a una economía neoliberal. Se describe a los shopping centers como grandes artefactos asociados a la globalización; globalizados y globalizantes, como máquinas de consumo en masa, como cajas genéricas (Chung, Koolhas et al. 2001; Sorkin, 2004) o "elefantes blancos" amurallados, uniformizadas y estandarizadas en todo el mundo (Borja, 2002), como arquitecturas que niegan la ciudad y colonizan otras formas y dinámicas antes existentes en el espacio público (Borja \& Muxí, 2000; Sorkin, 2004), espacios que segregan a usuarios que no tienen el poder adquisitivo suficientemente alto como para consumir (Harvey, 2004) y como escenarios que crean una "falsa idea de democracia e inclusión social" (Sarlo, 2009) al engañar al usuario haciéndolo pensar que tiene acceso a la mercadería aunque esta sea solamente visual.

Los autores (Chung, Koolhas et al. 2001) resaltan que las ciudades son revitalizadas a partir de su planificación como un shopping center. Añaden que el shopping center ha desencadenado una serie de modificaciones en el entorno construido para recibir e inducir a las actividades de consumo. En su interior, la naturaleza, el clima y las distancias artificiales envuelven al consumidor para incentivarlo a mantenerse ahí y comprar.

El Shopping ha ejercido una influencia sobre la forma de vida de la gente. Alcanza densidades que la hacen funcionar como un espacio urbano, o un paisaje más que como una arquitectura. Utiliza mecanismos de manipulación del entorno como estrategia para aumentar los niveles de consumo. Según los autores,

"Utilizando lo conocido para propagar la distracción sensorial, se deteriora el sentido crítico del comprador y se erosiona su resistencia a gastar. En este paisaje del shopping, la naturaleza - la inversión ideológica de la cultura - ha sido convertida en mercancía" (Chung, Koolhas et al. 2001). 
Jordi Borja, en su texto Ciudadanía y espacio público (1998), argumenta que en las ciudades se ha extendido y esparcido una enfermedad, producida por la desaparición y degradación de los espacios públicos de las ciudades, llamada por él como "agorafobia". Explica que la terapia o la alternativa para disminuir los síntomas de esta enfermedad, es la instalación de nuevos ghettos urbanos, como los shopping centers, que segmentan y fracturan el territorio y las relaciones sociales.

En relación a segmentación de la ciudad, Borja y Muxí (2000) explican que la diseminación de los centros comerciales, así como la de otros centros especializados, en los territorios metropolitanos, ordenan la vida según la dialéctica de la movilidad y las centralidades especializadas y cerradas en donde la ciudad funciona exclusivamente con el vehículo privado incentivando el individualismo y la exclusión de lo diferente. En este contexto, los autores añaden que la "domesticación del espacio" a través de la privatización y la "purificación" (de los no deseados) involucra exclusiones sociales acrecienta la desigualdad.

Regresando a la enfermedad de "agorafobia", se presenta a los centros comerciales como una "caricatura" de un centro urbano; un parque temático donde todo está controlado y donde el primer y último fin es el de lucrar con el consumo de la gente, manipulando sus actividades y necesidades, recreando un paraíso de aceptación en una cultura del miedo a ser rechazados. Una ciudad donde los promotores construyen estos grandes complejos comerciales, y comprar grandes parcelas de suelo a su alrededor para poder especular con el costo de la tierra, y así poco a poco la ciudad deviene en un territorio "planificado" por agentes privados (en conjunto con el gobierno y otros promotores) y configurado por la sumatoria de estos emprendimientos, "[...] más fragmentada, desagradable e ineficiente [...]" (Barnett, J. 1996 in. Borja y Muxí, 2000) que una ciudad sin planificación.

Esta corriente de "satanización" del shopping center pertenece, en su mayoría, a discursos académicos que coinciden con la crisis del espacio público, con el fortalecimiento de una sociedad individualista y globalizada (Ascher, 2007; Harvey, 2004), la expansión del neoliberalismo y la producción de la ciudad por agentes privados, al alto nivel de consumo en lugares de encuentro colectivo (Bauman, 2000; Dupuy, 1998), a la construcción de la ciudad como un parque temático (Sorkin, 2004) que recrea la vida pública de las plazas y las calles en un ambiente cerrado y controlado y como arquitecturas que son estrictamente financieras que están reconfigurando el paisaje y reordenando las ciudades (Chung; Koolhas; et al, 2001).

Desde el área de la sociología urbana, Ascher (2007) explica la ciudad contemporánea está liberada de los límites espaciales y temporales, puesto que la proximidad y la presencia física son cada vez menos necesarios para el intercambio y para las prácticas sociales. Es decir, el desplazamiento físico es cada vez menos necesario. Por otro lado, acrecienta que por la tecnología, las personas tienen la posibilidad de realizar simultáneamente varias actividades y de estar presentes en varios lugares al mismo tiempo.

Esto ha provocado la "deslocalización" (Ascher, 2007) o la desterritorialización de las actividades humanas donde los individuos pueden desplazarse por universos diferentes en cuestión de segundos. En otras palabras, el espacio físico no es fundamental para ningún tipo de intercambio, y el tiempo es relativo puesto que se multiplica por la simultaneidad de eventos posibles. Esta posibilidad de interacción a distancia espacial ha debilitado los encuentros sociales en lugares físicos y en consecuencia ha modificado la naturaleza de "lo local". Esta noción de pérdida de un centro espacial de encuentro para las prácticas sociales incentiva la homogeneización de la sociedad en espacios globalizados. En este contexto, los arquitectos participantes en el Harvard Project on the city argumentan que:

"Las galerías comerciales han reemplazado a los parques y las plazas que fueron "tradicionalmente el lugar de la libertad de expresión...El fluido vital de la economía, que en tiempo estaba en el centro de la ciudad, se ha trasladado a los centros comerciales de la periferia, los cuales han desplazado a los distritos de negocios del centro como lugares de la actividad social y comercial... La característica predominante de su comportamiento es la capacidad de incorporarlo todo. En esas galerías comerciales se encuentran la mayoría de los usos y actividades que llevan a cabo los ciudadanos fuera de sus casas...En su interior ni sólo hay tiendas de todo tipo y tamaño, sino grandes espacios abiertos a disposición del público, útiles para múltiples usos, Hay espacios para vagar, para sentarse y para hablar"." (Chung; Koolhas et al. 2001)

El desarrollo económico de las ciudades esta, cada vez más, relacionado con la accesibilidad a bienes, a 
información, y al transporte, así la logística se convierte en una función clave para su abastecimiento y consumo. Esta realidad ha dado origen a la pérdida de importancia de la proximidad en la vida cotidiana; la ciudad ha facilitado el desplazamiento a mayor velocidad con las grandes infraestructuras para el transporte y los barrios han dejado de ser el lugar de integración de las relaciones sociales. Así, lo local cambia de naturaleza, de sentido, de forma y de escala, y como resultado surgen nuevas formas de segregación social.

Un primer ejemplo de esta segregación son la formación de guetos donde la gente se agrupa por diferentes mecanismos económicos, sociales, étnicos y políticos (Ascher, 2007). La posibilidad de elección facilita la reagrupación de la sociedad en comunidades cerradas que buscan el "amurallamiento" de "su espacio". En el contexto de estas comunidades especializadas únicamente en vivienda amurallada, el shopping center encuentra su target fundamental para el éxito como "receta" de reactivación del encuentro social.

Según Bauman (2000), el consumo se ha tornado central en la vida de las personas, el propósito de su existencia misma, y poder experimentar emociones de querer, desear y anhelar y se ha convertido en el fundamento de la economía en las ciudades y sobretodo de las relaciones humanas. A esto le llama consumismo, que a diferencia del consumo, es un atributo de la sociedad; una ocupación del individuo humano para satisfacer los deseos, ganas, aspiraciones a partir de la apropiación y posesión de bienes que aseguren el confort vendido por una sociedad donde "la cantidad es poder", "lo diferente es excluido" y "siempre se crean nuevas necesidades y deseos en los imaginarios sociales" y, por tanto, todo debe ser estandarizado y homogeneizado y posteriormente desechado para volver al mismo ciclo de consumo (Bauman, 2000).

Para poder cubrir con estas nuevas necesidades y deseos creados por un sistema consumista es necesario crear un ambiente que entregue a los individuos una sensación de bienestar y de saciedad en un espacio al que Sorkin (2004) Ilama de parque temático. Un lugar donde todo está absolutamente controlado para satisfacer a los usuarios. El modelo más claro es el del formato Shopping Center que se ha propagado a otras dimensiones de la vida y a otros espacios como fue mencionado al inicio de éste título.

A partir de estas reflexiones, se genera una corriente de "satanización" del Shopping Center como el ejemplo más claro de anti-ciudad. Su expansión fue observado y analizado como parte de un proceso de especialización de la vida urbana (Marrero, 2008) y como un efecto de enclaustramiento de la vida social pública (Delgado, 2007), donde si bien la recreación, el entretenimiento y el consumo favorecen al público usuario, es un espacio controlado que pasteuriza y controla cualquier dinámica de espontaneidad o diversidad que se salga de los límites que no favorezcan a las transacciones comerciales en masa (Sarlo, 2009).

Marrero (2008) identifica que la crisis del espacio público ha provocado la interiorización de las actividades urbanas en arquitecturas especializadas que han sido insertadas en asentamientos especializados, generalmente en vivienda. Esta interiorización de las actividades provoca la desertificación de las plazas, parques, calles y otros espacios públicos que estaban convirtiéndose en espacios inseguros, ruidosos, sucios, y sin lugar para protegerse de las inclemencias del clima. El shopping center, por otra parte, pretende eludir todos estos "malestares" de la ciudad (Delgado, 1998; López-Levi, 1999).

Es importante destacar los discursos de Capron y Sabatier (2007) que afirman que los shopping centers, cada vez con mayor intensidad, buscar recrear espacios abiertos, calles y plazas públicas que produzcan bienestar como una estrategia meramente mercantil de consumo. El consumir constituye parte fundamental de la participación de los usuarios, y como resultado, se convierte en una nueva manera de ser un ciudadano (Canclini, 1995).

Por otra parte, López-Levi (1999) describe al shopping center como un espacio de múltiples simulaciones: una plaza, un lugar de esparcimiento, un lugar de compañía, un lugar de inclusión, una comunidad. Adicional a esto, Caprón y Sabatier (2007) sugieren que estas formas que adopta el shopping center responden una "nostalgia" de la ciudad clásica o idealizada. En consecuencia, el shopping center contribuye a mantener un cierto grado de vida pública en un espacio privado, y como resultado, incentiva a la privatización de la vida urbana.

Los shopping centers han fomentado un tipo de sociabilidad parecida a la de los espacios públicos tradicionales, sin embargo intensifican la diferenciación social propiciada por el contexto de consumo (Medina, 1997; Sarlo, 2009). Como señala Hernández Espinosa (2012), en el área de la antropología 
urbana, la democratización del shopping center no es más que un simulacro que agudiza la fragmentación social mediante las dinámicas del mercado global y el acceso (o no) a la mercadería. Así, los usuarios que no se ajustan a las normas y pautas de comportamiento y consumo, son excluidos (Medina, 1998), a pesar de que permite que tengan la sensación de "pertenecer" a una comunidad homogénea.

Desde estas óptica, en el ámbito latinoamericano, existen fuertes críticas también (Sarlo, 2009) que se enfocan en la fragmentación y segregación socio-espacial que incentivan estos artefactos de consumo. La autora argumenta que el shopping Center latinoamericano a sustituido a la ciudad, pues se ha encargado de reemplazar todas las dinámicas que ocurrían en el espacio público; en las plazas, en las calles, y las ha trasladado al interior de una caja cerrada, privatizando el espacio urbano de encuentro colectivo; un espacio que ha reemplazado a la ciudad y sus espacios tradicionales de encuentro, de recreación y de intercambio.

Esto ha provocado modificaciones importantes en la estructura espacial de las ciudades puesto que se modifican las jerarquías, transformando las lógicas de la planificación urbana en diferentes escalas; una ciudad privatizada (Lulle y Paquette, 2007).

La velocidad en la que es transmitida la información hoy en día, ha provocado un "exceso de saber" (Lipovetsky y Serroy, 2014) que ha complejizado las formas de vida. Ha creado una ansiedad insaciable por tener todo a lo que se tiene acceso (sensorialmente), y esto ha provocado que comportamientos cotidianos como comer, jugar, hacer deporte, descansar y entretenerse se hayan mercantilizado y materializado en un solo espacio donde consumir se ha convertido en el fin de todas las actividades humanas.

\subsection{Oportunidad}

En esta segunda corriente, que representa un opuesto a la anterior corriente presentada en esta tesis, se discute el fenómeno del Shopping center como una serie de espacios que permiten el desarrollo de nuevas formas de apropiación, de sociabilidad, de oportunidad para encontrarse entre diversos usuarios y de diversidad de actividades. Este discurso coincide con discursos entusiastas del origen del Shopping Center en 1956 (presentados en la introducción de esta tesis), y se lo retoma a partir de inicios de la década de 1990 con la crisis del espacio público a nivel global.

Varios autores argumentan que el Shopping Center enriquece el espacio urbano a partir de las nuevas dinámicas de sociabilidad que permiten (independiente de que sean dentro de espacios urbanos privados) (De Solá Morales, 1992; Secchi, 2013)

Manuel de Solá Morales (1992) defiende en su texto que los límites entre los espacios públicos y privados de encuentro colectivo se han disuelto cada vez con mayor intensidad. Argumenta que los espacios públicos para ser efectivamente apropiados, requieren de los comercios, las viviendas y los equipamientos privados como envolventes o como componentes esenciales para garantizar la co-presencia en ellos. Todas estas actividades que se desarrollan en el espacio privado es lo que incentiva la efectiva apropiación de los espacios públicos, y de igual manera, añade que lo privado sólo tiene sentido cuando se encuentra en estrecha relación con el espacio público.

En paralelo a este texto, Manuel de Solá Morales junto con Rafael Moneo diseñan y construyen el primer centro comercial de Barcelona: Illa Diagonal. Este edificio se materializa e inaugura en 1993 como la conclusión final de su escrito donde resaltaba lo importante que era el espacio colectivo, que facilite la sociabilidad, el encuentro, el entretenimiento, el acceso a servicios y al comercio, independiente de que sea público o no. Además, el centro comercial Illa Diagonal fue presentado como una intervención de regeneración urbanística, iniciando así, el discurso del shopping center como una nueva forma de producir ciudad de calidad.

El shopping center Illa Diagonal es un contenedor de diversos usos en diferentes escalas. Incluso ha sido descrito por sus creadores como un portador de centralidad, por el grado de diversidad y flexibilidad (de usos y usuarios) y de concentración de personas, actividades, situaciones y dinámicas que facilita. Un edificio con una tensión entre la unidad y compactación y la diversidad de usos. Los usos adicionales a las galerías comerciales son: oficinas y un hotel, todos con sus parqueaderos y accesos propios. Así, el shopping center Illa Diagonal, fue concebido como un proyecto de regeneración y activación de un barrio de Barcelona.

En la narrativa de esta corriente existen autores que resaltan los elementos positivos que ha tenido la 
construcción de estos espacios y concluyen que el shopping center puede contener la vida pública de la ciudadanía, construyendo nuevas identidades y valor simbólico, incentivando cada vez más la diversidad. En el contexto latinoamericano la literatura es más reducida, sin embargo algunos autores, tal como Manuel de Solá Morales (1993), analizan al shopping center como nuevos gérmenes de centralidad urbana que aglomeran mucha más diversidad de usos y usuarios que muchos de los espacios públicos de las ciudades (Cáceres, 2006; Sabatini, 2006; Salcedo, 2003)

Los usuarios de los shopping centers, buscan no solamente satisfacer su necesidad de compra, sino también, entrar en co-presencia. Encontrarse como parte de un colectivo, sin perder su condición de individuo. El anonimato en el que se puede experimentar el shopping center es una de las condiciones positivas que rescatan Sandicki y Holt (1998). Resaltan que es interesante observar a la gente ir solamente a "vitrinear" y a mantener un mínimo de contacto con los vendedores; Sentirse acompañados sin sentirse invadidos. Por otro lado, Feinberg et. Al (1989) destaca la interacción social en los Shopping Centers es tan relevante como lo fue en las ferias públicas tradicionales. Los consumidores entienden al shopping center como un espacio de interacción controlada por ellos.

A partir de estudios realizados por Salcedo y Stillerman (2003) concluyen que los shopping centers son espacios diversos donde es posible construir identidades de clase o etáreas. Niegan que el shopping center es un lugar que aniquila lo cotidiano puesto que, la gente asimila los espacios y transponen prácticas de otros espacios de encuentro colectivo. Lo habitan y se refieren a él de una manera muy familiar.

De igual manera Haytko y Baker (2004) sostienen que los niños, adolecentes y padres jóvenes visitan el shopping center para socializar, para jugar, para esparcirse. La posibilidad de no sentirse vulnerables o alertas del peligro facilita la sociabilidad entre los grupos de niños que se reúnen a jugar en los espacios destinados a ellos mientras sus padres conversan o comen. Así, Los académicos están cada vez más interesados en el shopping center como espacio lúdico que invita a los usuarios a no sentirse vigilados u observados y permite un comportamiento autónomo (Kozinets et al., 2004; Holt, 1995).

La cantidad de personas que se reúnen en el patio de comidas, a comer comida llevada desde su hogar o comprada en los patios de comidas, no necesariamente van a realizar compras de bienes (más allá de lo que fueran a comer). Las relaciones familiares son evidentes en estos espacios que poco a poco van siendo "domesticados" por sus usuarios para hacerlos más "familiares" (Salcedo y Stillerman, 2003)

Urteaga y Cornejo (1995) argumentan que los jóvenes se apropian de los espacios públicos y los transforman en territorios con una carga simbólica para manifestarse y construir identidades. Los espacios donde pueden sentirse escuchados, donde se identifican con un colectivo de gente con sus mismos ideales, donde se sientan protegidos por actores similares a ellos y más que nada donde se sientan importantes como individuos más allá de su importancia como grupo.

Los autores sostienen que el shopping center puede disfrutar, al igual que los niños, un cierto grado de autonomía y se sienten no vulnerables al peligro. Esto ha provocado que se manifiesten dentro del territorio del shopping center, construyan discursos e identidades que les reafirman su pertenencia a la ciudad (Cornejo, 2000). Según Cornejo (2000) "los visitantes son agentes creativos que utilizan el mall para sus propios fines, generando prácticas de resistencia, o de co-producción del espectáculo comercial"

"Al momento de construir y "escenificar" una identidad de clase en el mall, y de formar límites con el resto, las personas se ven obligadas a "interpretar", y las posiciones de clase del resto de los visitantes, dentro de la cual la conducta y la apariencia física son claves. Así, a fin de evitar la estigmatización por parte de guardias y empleados del mall, muchos adolescentes de clase media baja se convierten en estigmatizadores, juzgando a grupos de clase baja o miembros de tribus urbanas que buscan también hacer del mall un espacio propio donde pueden construir y manifestar su propia identidad." (Salcedo y Stillerman, 2003)

\subsection{Detonante}

Esta tercera corriente (que coincide con discusiones más contemporáneas), discute narrativas científicas que identifican al Shopping Center como un fenómeno que ha provocado transformaciones en la ciudad; en su forma, en su lógica de circulación de información, de bienes y de personas, en el reordenamiento de usos, y en el comportamiento de sus usuarios. 
Varios de estos autores incluso critican a la narrativa "romántica" de un espacio público inclusivo y democrático (que en muchos casos fueron segregadores de algunos grupos sociales) y lo analizan desde un punto de vista objetivo (Crawford, 1999; Delgado \& Malet, 2013, De Solá Morales, 1992) Así, despierta un mayor interés por el Shopping Center, visto desde la óptica de un equipamiento que responde eficientemente a las necesidades contemporáneas de encuentro social, de abastecimiento, de recreación y de ocio (Koolhas, 2006; Wall, 2005), trayendo nuevamente a discusión argumentos de publicaciones de Víctor Gruen (Wall, 2005), arquitecto que da origen a la esencia del Shopping Center.

Desde esta corriente, los discursos consideran un error juzgar al shopping center como un símbolo de la privatización de los espacios de encuentro colectivo, como una "victoria" del sistema económico neoliberal, o como un objeto genérico homogeneizado en todo el mundo independiente de la cultura en donde es insertado (Crawford, 1999) y resaltan que el shopping center debe ser estudiado y analizado con la prolijidad y la profundidad que debe ser analizado cualquier objeto urbano-arquitectónico.

En el ámbito latinoamericano, también resaltamos los discursos de Salcedo (2003) y de De Mattos (1999) quienes discuten la capacidad de adaptación de los Shopping Centers a las transformaciones y al desarrollo de las ciudades. Esta adaptación, ha venido incentivando un mayor diálogo y relación entre el Shopping Center y la ciudad, materializándose en transformaciones morfológicas en diferentes escalas.

Para varios autores los shopping centers construyen nuevas lógicas urbanas al constituir nuevos potentes polos de atracción (en zonas de alto, medio y bajo poder adquisitivo), generando fuertes tensiones en las ciudades, lo que genera transformaciones en los modelos urbanísticos de estructura espacial (Cáceres, 2006; Sabatini, 2006; Salcedo, 2003, 2006).

\section{EL QUICENTRO SHOPPING CENTER}

En el contexto del estudio de caso, después de más de cincuenta años de la construcción del primer shopping center a nivel global, y de casi 30 años del surgimiento del primero en el Ecuador (Figura 1), el shopping center se había convertido en un nuevo espacio de sociabilidad, intercambio y encuentro colectivo, antes imaginado únicamente en el espacio público.

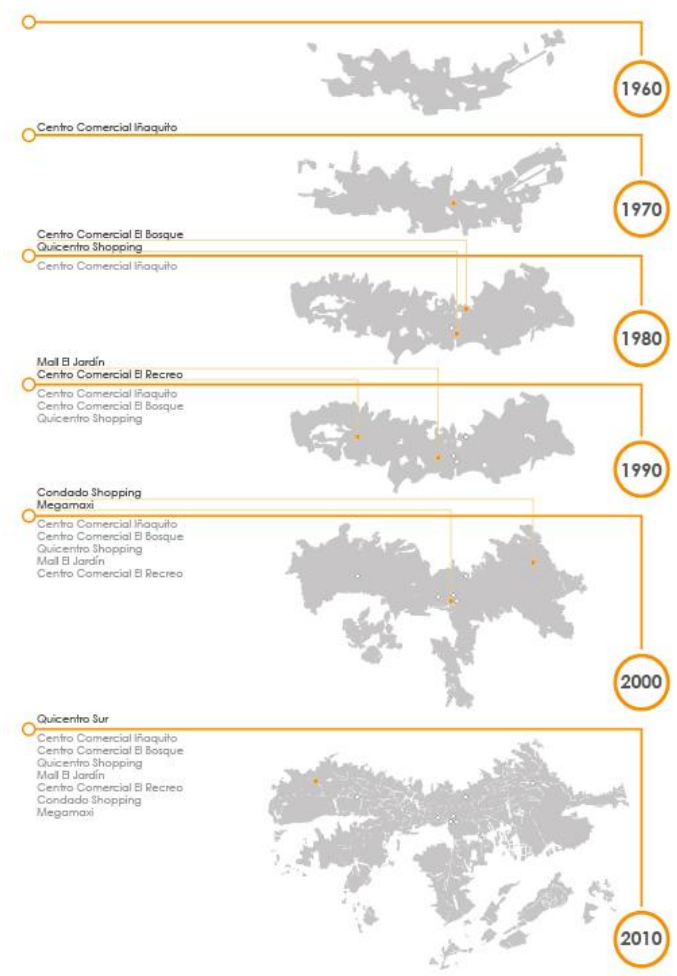

Figura 1. Crecimiento de la mancha urbana de Quito y aparecimiento de los shopping centers.

Fuente: Elaboración propia a partir de los planes de ordenamiento territorial desde 1970 hasta el 2010 y levantamiento de los shopping centers. 
El Ecuador entra en un período democrático en la década de los ochenta, y se inicia la inauguración de los shopping centers en su capital Quito. El shopping center se vuelve parte de la memoria colectiva de los encuentros colectivos de la sociedad y un espacio de encuentro, sobretodo para los jóvenes capitalinos. El Quicentro Shopping Center se enclava en la memoria colectiva de los quiteños; era un nuevo espacio donde se sentían libres de consumir, de observar y de circular por donde quisieran. Además, es el primer shopping center concebido como un shopping center pericentral y suprarregional, con tiendas ancla y con patio de comidas, de la capital del país, insertado en una zona planificada como el centro financiero del Ecuador.

Según Peralta y Moya (2008),

"En Ecuador los bancos poco a poco abrieron su cartera hipotecaria, impulsando de esta manera la construcción de nuevos complejos comerciales como el Quicentro Shopping [...] que dieron origen a la creación de un gran centro financiero y de negocios que se desarrolló alrededor del parque de La Carolina."

Así, el Quicentro Shopping Center (1987), junto con el Centro Comercial Iñaquito CCI (1971) y el Centro Comercial El Bosque (1982) eran los nuevos espacios comerciales, de entretenimiento y de esparcimiento de la ciudad, modificando las dinámicas de desplazamiento (antes hacia el centro tradicional de la ciudad), las formas de diversión y las formas de encuentro colectivo. En palabras de Peralta (2008),

"Una de las edificaciones más destacadas estuvo a cargo del Grupo Wrigth, con la construcción del Centro Comercial Iñaquito (CCl) en 1971, el cual empezó como un proyecto pequeño con 10 locales comerciales. A partir de entonces, todo el sector norte y sus alrededores tuvieron un crecimiento paulatino, ya que este centro comercial fue un imán que dinamizó la zona en lo cultural, social y económico, y por ende impulsó el desarrollo inmobiliario de esta zona."

Las características polémicas, simbólicas y de memoria cultural del shopping center ha provocado que su estudio se fortalezca a nivel global y ahora es estudiado no como un artefacto de consumo genérico, sino como un equipamiento que detona, fortalece y debilita ciertos usos, fenómenos y dinámicas en diferentes escalas en la ciudad.

En la ciudad de Quito, y en general en el Ecuador, la discusión de los Shopping Centers a nivel intelectual o académico aún no es un tema de preocupación o reflexión, más allá de las discusiones importadas de países europeos o norteamericanos donde se describe al shopping center o al mall como un espacio genérico que niega la ciudad sin articular los nuevos grupos sociales y los fenómenos que han producido en diversas escalas, más allá de la caja cerrada que niega el espacio público y que pertenece únicamente a una sociedad neoliberal, individualista.

Los académicos, actualmente, tenemos la oportunidad de estudiar al shopping center como un fenómeno social, como un espacio ideológico, simbólico y de construcción de colectividades. Es decir, estudiar el shopping center es una oportunidad para estudiar las transformaciones socioeconómicas del ecuador, su morfología y su funcionamiento.

Hoy en día, en el Ecuador existen varios shopping centers; en barrios con diferentes características morfológicas, funcionales, socioeconómicas y culturales y en las ciudades principales del país existe al menos uno; en la capital Quito existen actualmente ocho shopping centers (como pudo ser observado en la figura 1). Los más visitados tienen alrededor de 150 mil visitantes al día en promedio y se han convertido en espacios de socialización, de encuentro y de generación de nuevas identidades y nuevos colectivos. Además son espacios cotizados por la ciudadanía por el sentimiento de seguridad que generan y por su infraestructura que facilita las condiciones de la experiencia y disfrute de esta arquitectura y por la diversidad de lugares de consumo de diversos costos y de entretenimiento para diversos usuarios.

En el Ecuador, es evidente el abandono del espacio público y de los espacios culturales por diferentes motivos, y la preferencia al shopping center como espacio de entretenimiento, de ocio, de encuentro y de consumo, le da una "aprobación" visible y medible a partir del número de visitas, el número de compras y el valor de las compras. Por este motivo es importante estudiar estas arquitecturas en su medio y con su geografía propia para comprender las transformaciones de las ciudades en diferentes escalas con la inserción de los shopping centers. 
El Quicentro está localizado en el centro-norte de la ciudad de Quito, capital del Ecuador. (Figura 2). El Terreno original en donde se insertó el Quicentro Shopping center fue en un inicio una hacienda de 25,5 hectáreas dedicadas al pastoreo de ganado. Ya para la década de los años 70 se destina este terreno para la construcción de un proyecto de vivienda, y es cedida al municipio (por ordenanza) el 15\% del área total como espacio público (Figura 3).

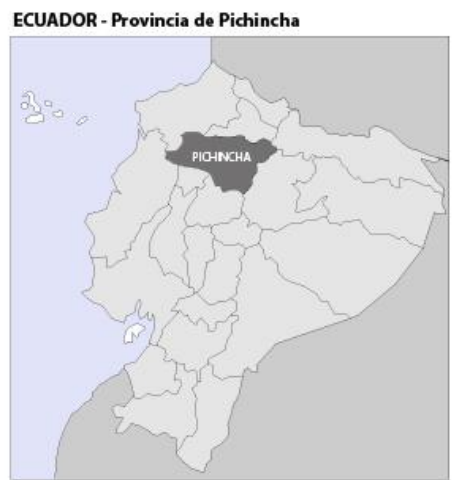

PICHINCHA - Distrito Metropolitano de Quito

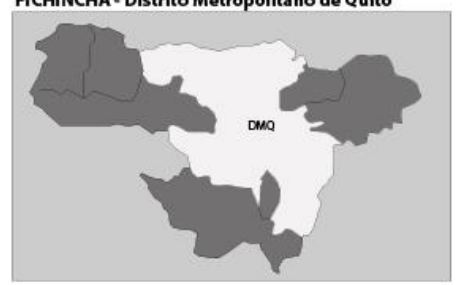

DISTRITO ME TROPOLITANO DE QUITO

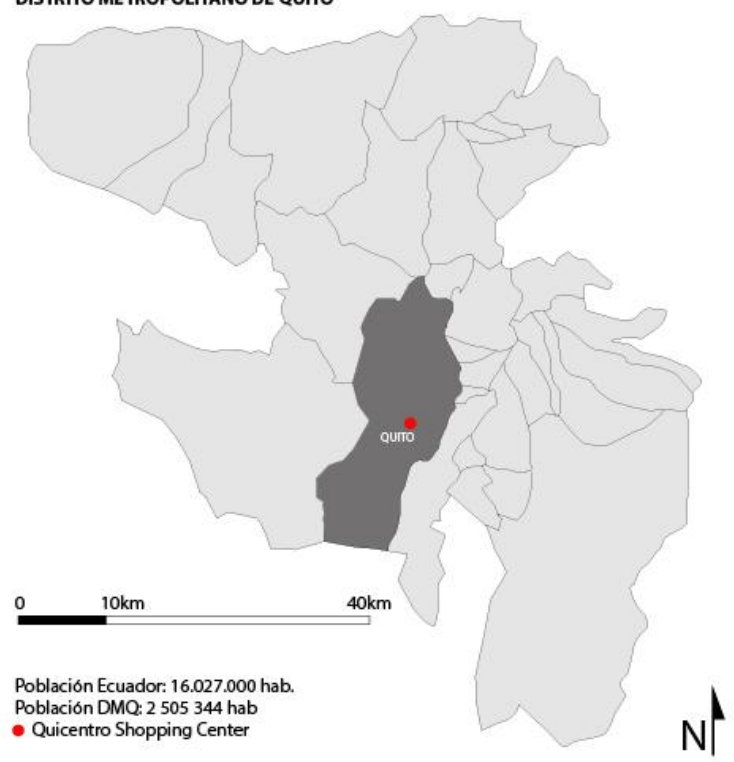

Figura 2. Localización del Quicentro Shopping Center en Quito - Ecuador.

Fuente: Elaboración propia a partir de mapas del Instituto Geográfico Militar del Ecuador.
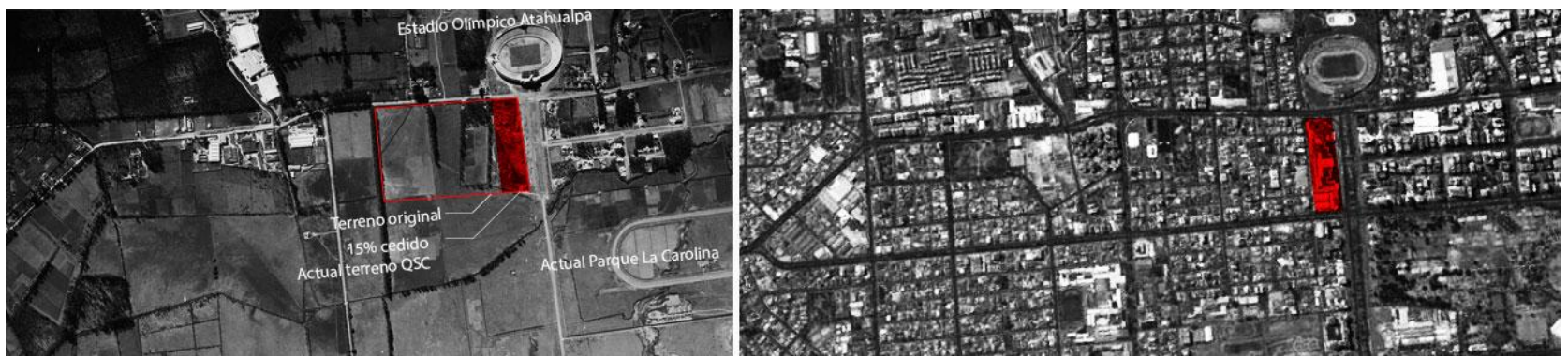

Figura 3. Lote original donde se inserta el QSC en los años 60 (izq.) y el lote actual (der.)

Fuente: Elaboración propia a partir de fotografías aéreas del Instituto Geográfico Militar del Ecuador, 2016.

En el año de 1977, el 15\% del terreno de 3,6 hectáreas es rematado por al Municipio de Quito con el nombre de "burro potrero" por sus características de pastoreo y finalmente vendido a Alberto Deller quien fue el primer presidente de la compañía que construye el Quicentro Shopping. Para este entonces el programa de vivienda aún no estaba consolidado, no había ningún desarrollo en el sector y solamente había una calle llamada Avenida de los Estadios (Actual Boulevard Naciones Unidas) que remataba en el Estadio Olímpico Atahualpa, construido originalmente como parte de un complejo olímpico que nunca se llegó a construir por falta de recursos a raíz de la crisis económica del país.

En 1982 A. Deller inicia la construcción del, entonces llamado, Centro Comercial Quicentro, con 30 almacenes; entre esos un supermercado, una panadería, una pizzería, un restaurante de pollo a la brasa, un club de Racquet y Squash, una megaferretería llamada Kiwi (muy famosa en el Ecuador) y Etatex que era una tienda ecuatoriana de ropa producida en serie. Estos locales, novedosos por su concentración en un sólo sitio atraían gente de toda la ciudad.

En el contexto de la ciudad de Quito, iniciativas de planes de vivienda se acogen al primer plan ordenador de Quito, el Plan de Jones Odriozola de 1942 el cual fue reactivado en 1967 y donde se precisaban los crecimientos en extensión y densidad urbana de la ciudad. En el primer documento de 1945 se recomienda separar las funciones de Quito por zonas para el futuro desarrollo (Peralta y Moya, 2008). 
El Plan dividía a la ciudad en tres principales zonas, la de vivienda, la de trabajo y la de recreación, recomendando la separación espacial y la diferenciación de usos de suelo. En este sentido, se plantea al sur de la ciudad como un sector industrial y de vivienda de interés social para obreros. Así, el sur, con participación del Municipio de Quito genera nuevos barrios en el sur.

El mismo plan propone que al norte de quito se expandan los programas de vivienda destinados a la clase con poder adquisitivo medio-alto y alto, y además que se constituya como el nuevo centro financiero y de ocio de la ciudad. Así, en los años 70 con el "boom petrolero" y un importante crecimiento de la economía ecuatoriana, la ciudad se empieza a extender hacia el sur con su centro industrial y obrero, y hacia el norte con un centro financiero y residencial de clase media-alta.

Se inicia en la misma década de 70 la construcción con hormigón, y esta importante iniciativa se materializa con la construcción de edificios destacados como del "movimiento moderno del Ecuador" por sus características, calidad y lenguaje arquitectónico. Dentro de estos edificios destacados, se construye el primer centro comercial de Quito, el $\mathrm{CCl}$ (Centro Comercial Iñaquito), el cual empieza como un proyecto pequeño de no más de 15 locales comerciales.

Peralta y Moya (2008) argumentan que a partir de la construcción del CCI todo el norte de Quito tuvo un crecimiento paulatino pues este centro comercial fue "un imán que dinamizó la zona en lo cultural, social y económico y por ende impulsó el desarrollo inmobiliario en la zona."

Después de una dictadura de cuatro años (1972 - 1976) el Ecuador regresa a la democracia con pocos recursos económicos que resultó en la austeridad extrema, condición que se vio reflejada en un mercado deprimido y en la disminución de la construcción. En este contexto se construye el segundo centro comercial de Quito El Bosque en 1982 el cual replica el modelo de desarrollo urbano de Bogotá con el Centro Comercial Unicentro (1976) el cual a raíz de su edificación, incentivó la urbanización de las zonas aledañas. Lo mismo ocurrió con El Bosque con el que después de su construcción se inició la urbanización con el mismo nombre (Peralta y Moya, 2008).

En la década de los 90 la economía ecuatoriana empieza un proceso de crecimiento, aunque lento y con una inflación alta, y así el sector de la construcción tiene la oportunidad de obtener créditos en instituciones bancarias y financieras (Peralta y Moya, 2008). El acceso a préstamos impulsa la construcción de dos nuevos centros comerciales, el Quicentro Shopping Center y el Mall El Jardín "[...] entre otras edificaciones, que dieron origen a la creación de un gran centro financiero y de negocios que se desarrolló alrededor del parque La Carolina (Figura 4). De igual manera, en 1995 con la edificación del Centro Comercial El Recreo, al sur de la ciudad, ocurrió el mismo fenómeno antes mencionado, ya que la plusvalía de las urbanizaciones que rodearon esta obra se incrementó notablemente." (Peralta y Moya, 2008).

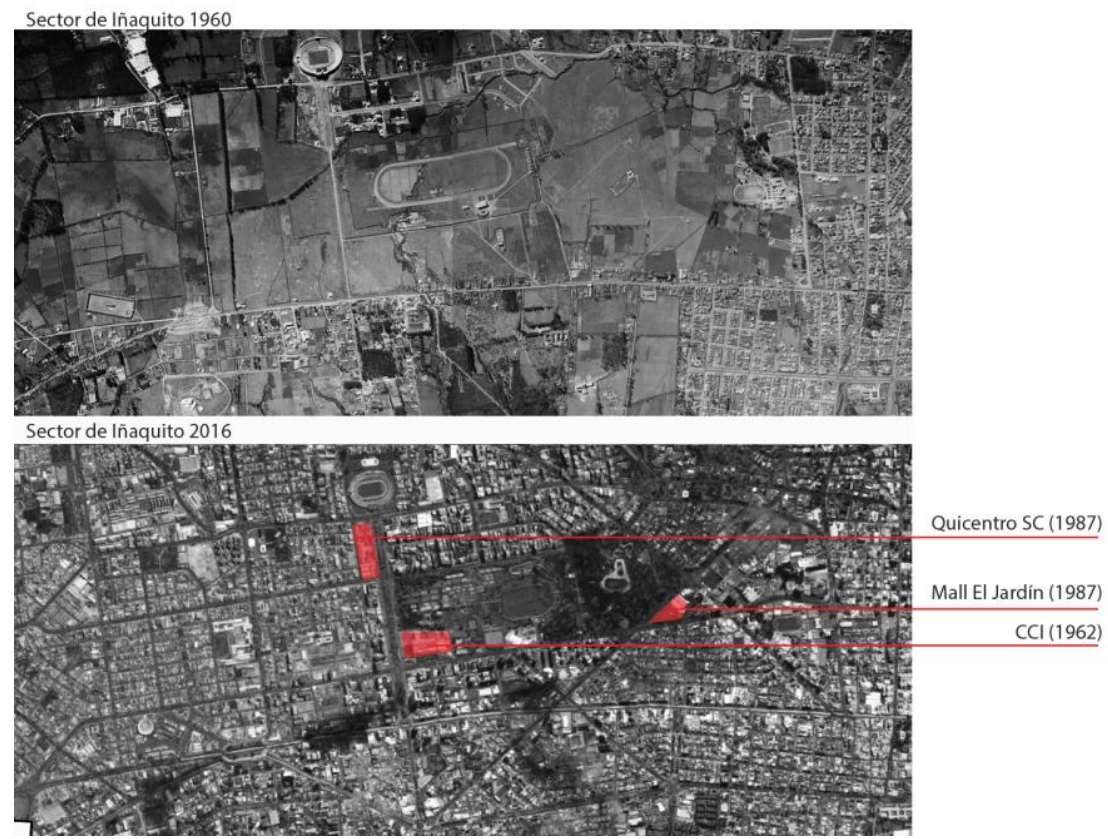

Figura 4. Crecimiento de la mancha urbana de Quito y aparecimiento de los shopping centers.

Fuente: Elaboración propia a partir de fotografías aéreas del Instituto Geográfico Militar del Ecuador, 2016. 
Posteriormente, en el año 2000, después de la dolarización de la economía ecuatoriana, "[...]una de las construcciones de mayor alcance se levantó al norte de Quito. El Condado Shopping fue una muestra de la activación económica y social que se ha desarrollado en ese sector." (Peralta y Moya, 2008). Diez años después se construyó el Quicentro Sur, el centro comercial más grande del Ecuador, que fue llamado Quicentro, al igual que el Quicentro Shopping Center del norte de Quito a petición de los habitantes de la zona de Quitumbe, donde sería construido (Viteri, 2016), "[...]Con la construcción de esta obra, se impactó social, económica y urbanísticamente en el sector (Figuras 5 y 6). Además, ha contribuido a centralizar servicios al ubicarlos en un solo lugar, y así evitar que las personas deban movilizarse a otros puntos de la ciudad." (Peralta y Moya, 2008)

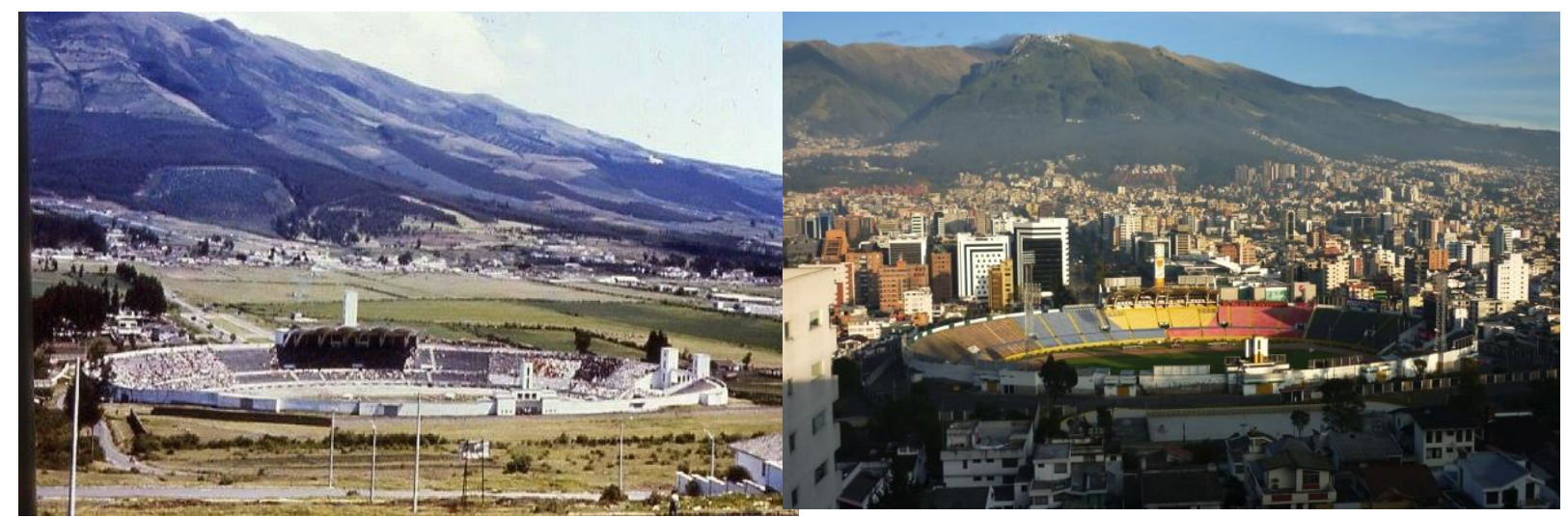

Figura 5. Sector de Iñaquito año de 1960

Fuente:

http://img205.imageshack.us/img205/7298/426272101506634211

Figura 6. Sector de Iñaquito año de 2014.

88905.jpg

\subsection{Espacio Concebido y Percibido del Shopping center - Escala Ciudad}

En esta escala, y desde el espacio concebido y percibido, se busca realizar un análisis gráfico de las planificación de la ciudad y su efectiva materialización, en diferentes períodos, a partir del uso de suelo, de la densidad poblacional, y al transporte masivo (BRT, metro y ciclovías) en relación a la inserción de los shopping centers en Quito, incluido el Quicentro Shopping Center.

Se realizó cartografía del uso de suelo, densidad y transporte a partir del análisis de la planimetría de los planes de ordenamiento territorial desde 1970 hasta el 2015.

\section{Uso de Suelo - Espacio Concebido}

En las figuras 7, 8, 9, 10 y 11 que corresponden al mapeo de usos de suelos planteados por los planes, se pueden observar las diferentes propuestas para la ciudad de Quito. Se verifica que conforme pasa el tiempo se plantea la consolidación un hipercentro en el centro-norte de Quito donde se concentra la mayor cantidad de uso de suelo múltiple. Es evidente también la propuesta de concentración de equipamientos (entre ellos parques, plazas y terrenos donde posteriormente fueron edificados los shopping centers). El uso de suelo residencial, en torno a los shopping centers, cada vez es modificado hacia un uso de suelo múltiple y el uso de suelo únicamente residencial disminuye en la mancha urbana próxima a estas arquitecturas. 

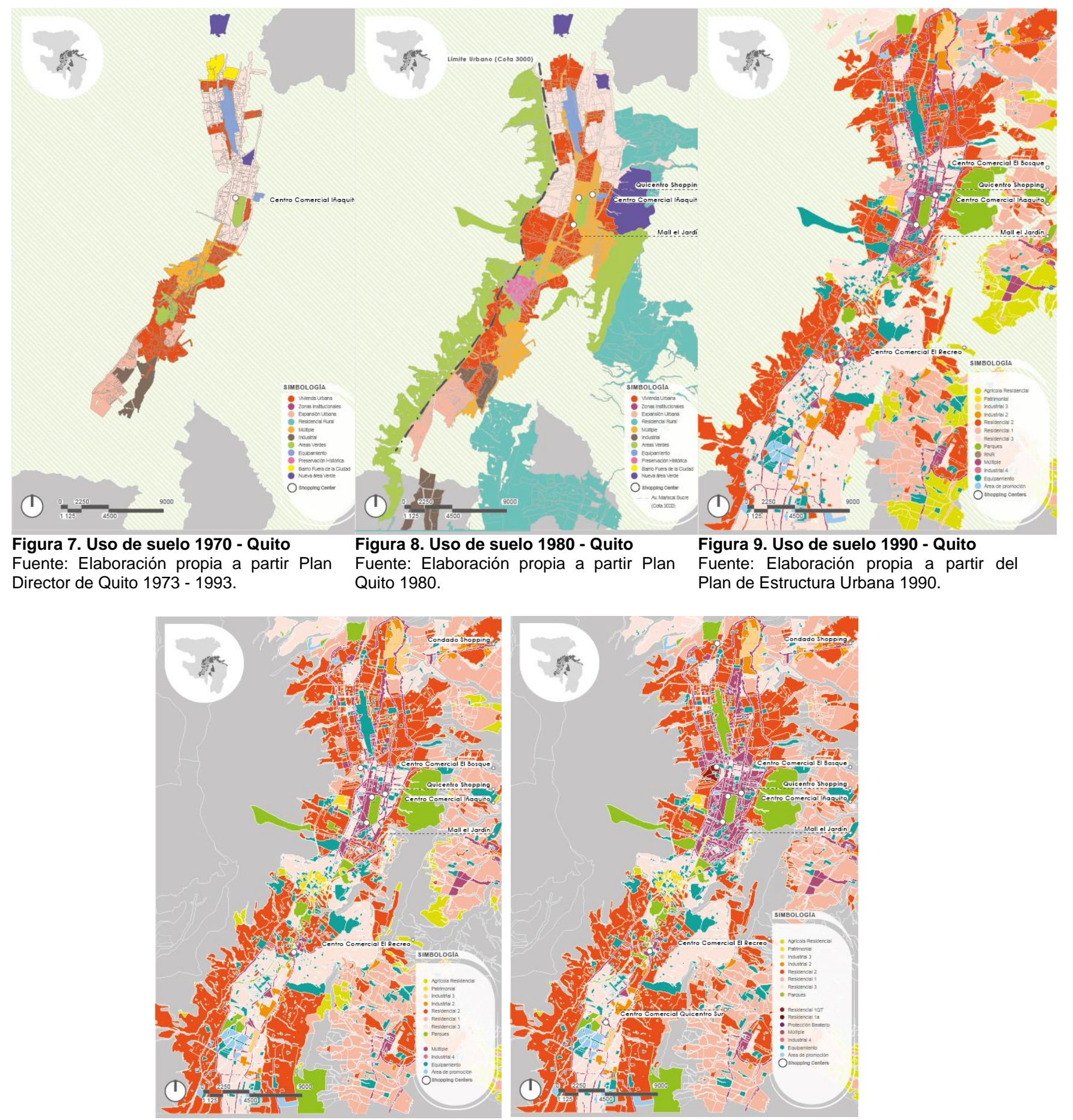

Figura 10. Uso de suelo 2000 - Quito

Fuente: Elaboración propia a partir del Plan General de Desarrollo Territorial 2000 2020.

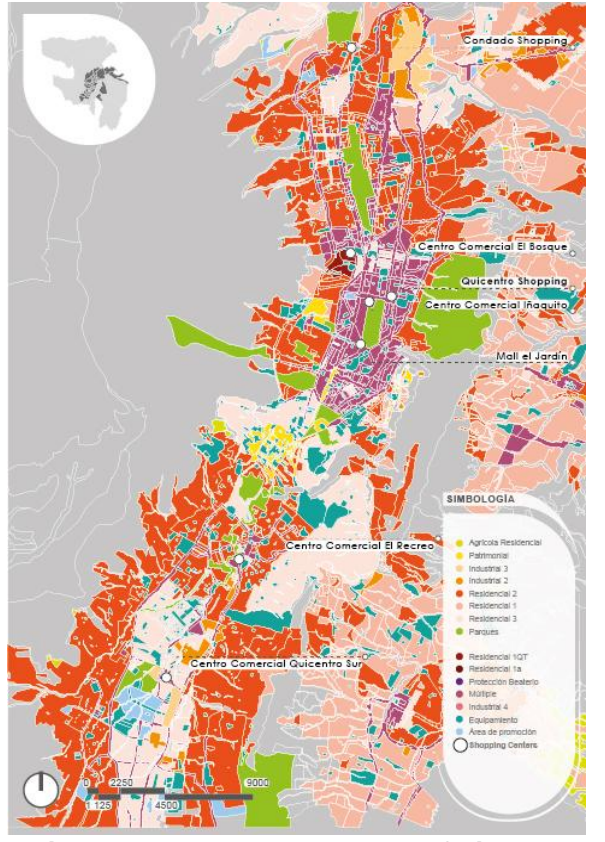

Figura 11. Uso de suelo 2015 - Quito

Fuente: Elaboración propia a partir del Plan de Desarrollo y de Ordenamiento Territorial, 2015.

\section{Uso de Suelo - Espacio Percibido}

En esta escala, y desde el espacio percibido, se busca realizar un análisis gráfico de las efectivas transformaciones de la ciudad con base en el uso de suelo, la densidad y el transporte masivo en relación a la inserción de los shopping centers, entre ellos el Quicentro Shopping Center.

Para esto se ha realizado un levantamiento del uso del suelo, la densidad y el transporte a partir del diagnóstico de los diferentes planes de ordenamiento territorial desde los 1970 hasta el año 2015.

En las figuras 12, 13, 14, 15 y 16 que corresponden al diagnóstico del uso de suelo de los planes de 
ordenamiento territorial de Quito de los años 70, 80, 90, 2000 y 2015, se puede observar las efectivas transformaciones del uso de suelo de Quito. Se verifica que conforme pasa el tiempo se consolida en el centro-norte de la ciudad, un hipercentro donde se localizan actualmente 4 shopping centers. Es evidente el aparecimiento y concentración de uso de suelo múltiple en torno a los shoppings centers y una disminución del uso de suelo únicamente residencial. También se puede observar que se concentran, en el mismo hipercentro, equipamientos (incluyen parques, plazas y shopping centers).

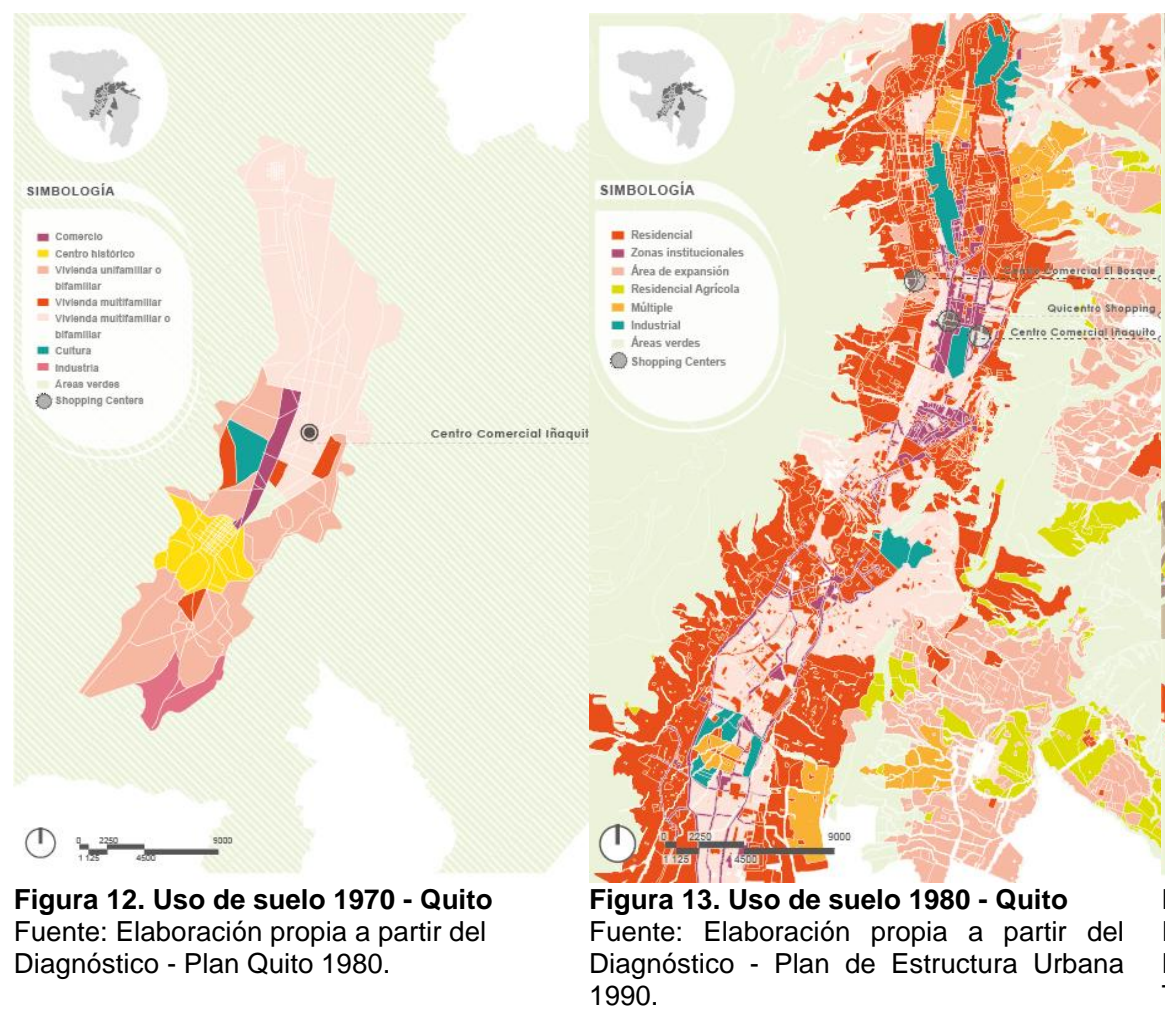

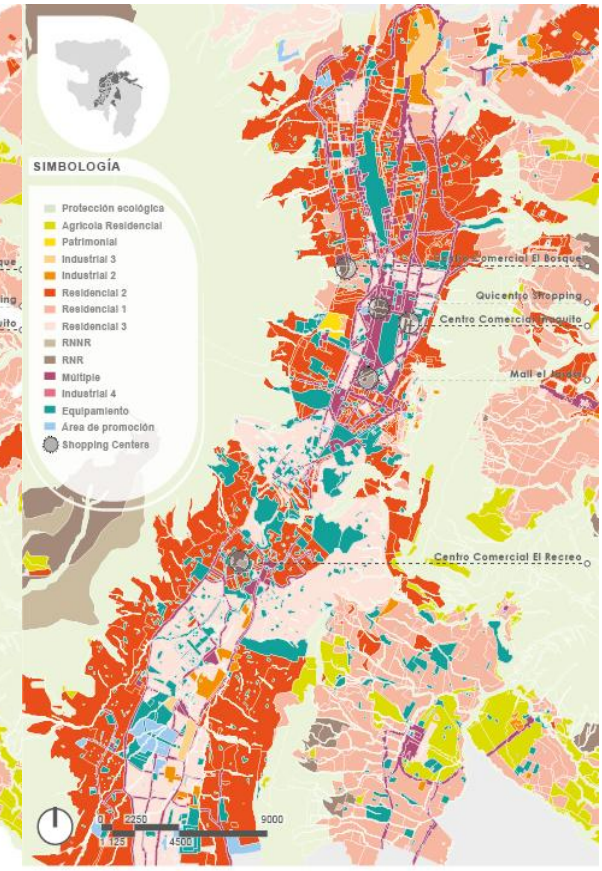

Figura 14. Uso de suelo 1990 - Quito

Fuente: Elaboración propia a partir del Diagnóstico - Plan General de Desarrollo Territorial $2000-2020$.

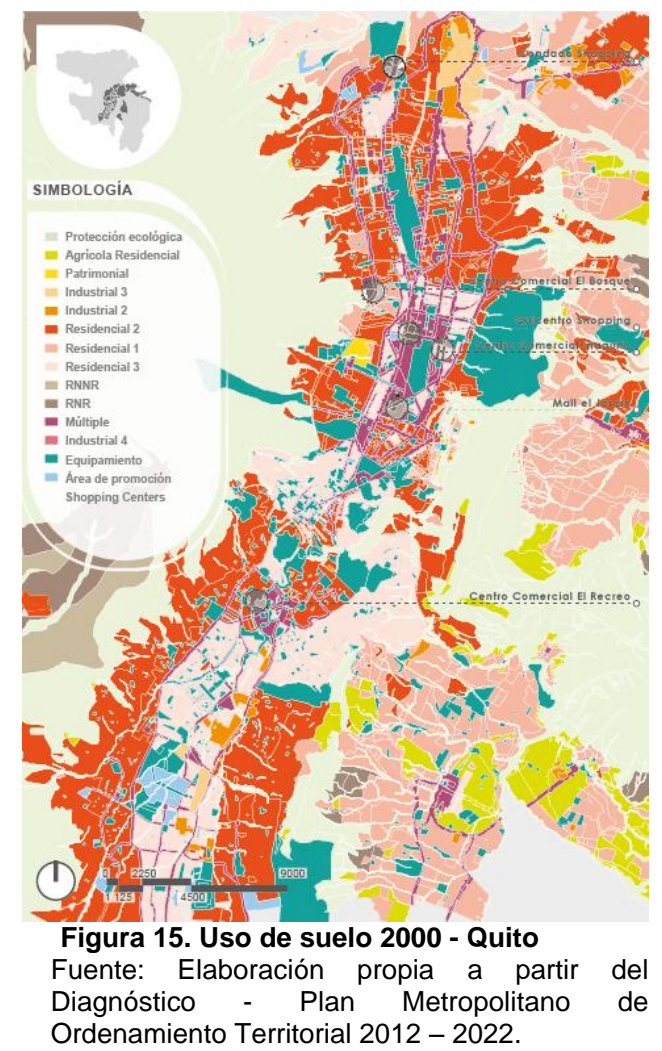

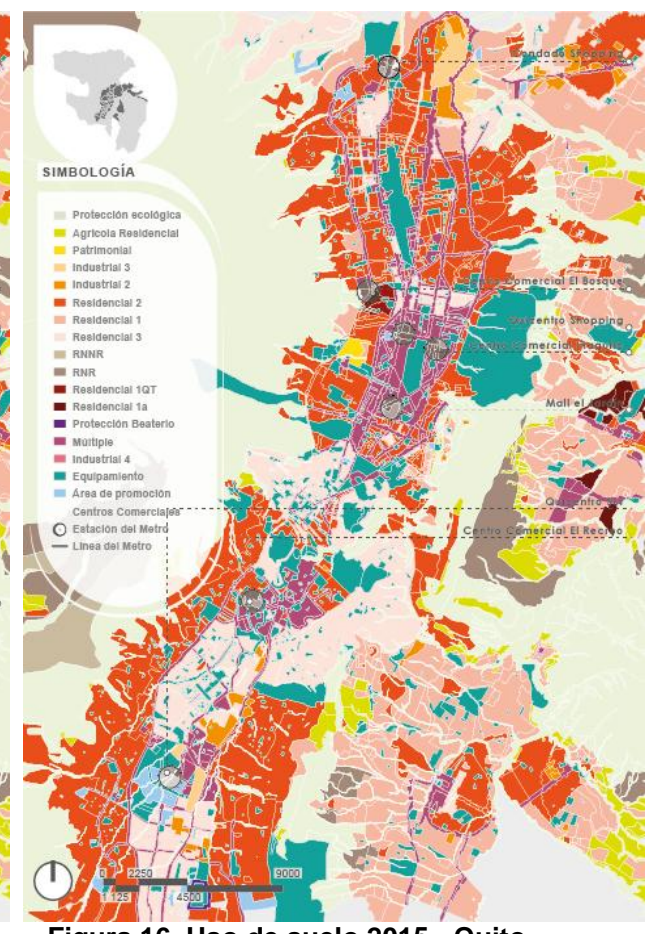

Figura 16. Uso de suelo 2015 - Quito

Fuente: Elaboración propia a partir del Diagnóstico - Plan de Desarrollo y de Ordenamiento Territorial, 2015. 


\section{Transporte - Espacio Concebido}

En este análisis se busca realizar un análisis gráfico de la planificación del transporte en Quito desde el año de 1970 hasta el año 2015 en relación a la inserción de los shopping centers, entre ellos el Quicentro Shopping Center. Se realizó la cartografía de la propuesta de transporte a partir de la planimetría de los planes de ordenamiento territorial desde 1970 hasta el año 2015 En las figuras 17, 18, 19, 20 y 21 se evidencian las propuestas de transporte planteadas.

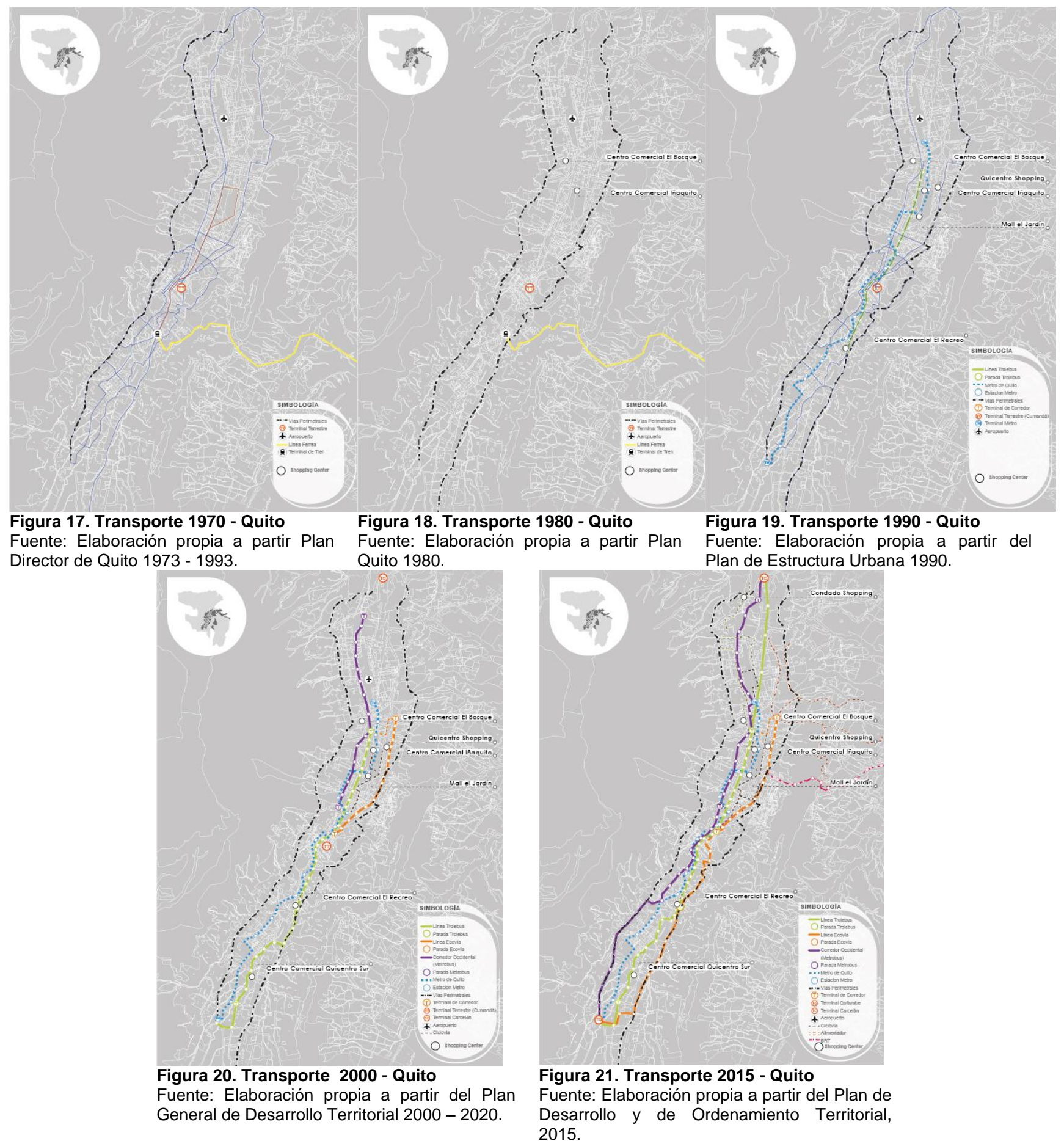

En el plan de los años 70 se puede observar la propuesta de la construcción de un terminal terrestre, y su articulación con el hipercentro en el centro norte de quito y con la estación del tren en el centro sur. En el plan de 1990 ya se plantea una línea de BRT longitudinal que conecta el hipercentro con el sur de la ciudad y también se propone la construcción de la primera línea de metro de la ciudad en el mismo sentido 
longitudinal y que atraviesa el hipercentro. Ya para el año 2000 se propone una nueva línea longitudinal occidental de BRT que articula el hipercentro con el norte de la ciudad, y posteriormente en el plan del 2015 se propone ampliar la misma línea de BRT hacia el sur y crear una nueva línea de BRT oriental, también en sentido longitudinal que articula el hipercentro con el sur de Quito y un circuito de ciclovías que se concentran en el hipercentro. También se plantea la creación de una nueva línea de BRT que conecte con el área metropolitana oriental. Se verifica entonces, que desde la planificación se plantea la consolidación del hipercentro con su accesibilidad y también a los centros donde están localizados los shopping centers a través de la articulación con diferentes medios de transporte masivo.

\section{Transporte - Espacio Percibido}

En las figuras 22, 23, 24, 25 y 26 se puede observar la efectiva construcción de los sistemas de transporte y sus terminales y estaciones.

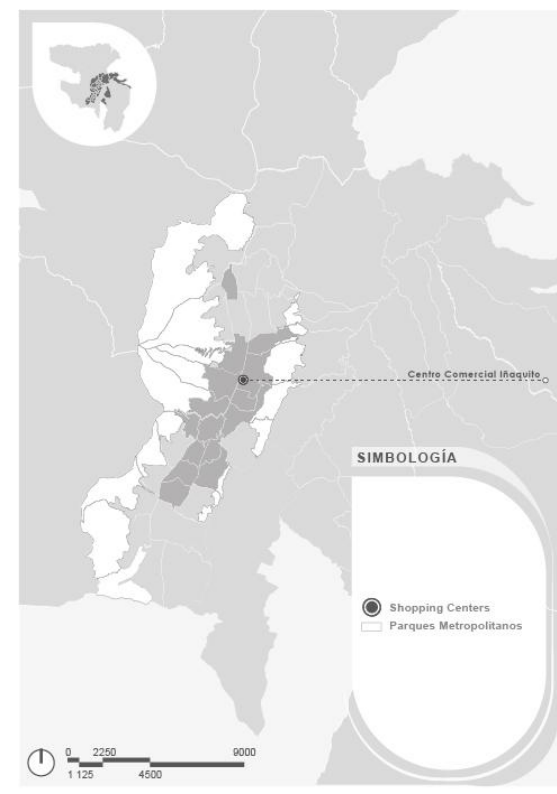

Figura 22. Transporte 1970 - Quito

Fuente: Elaboración propia a partir del Diagnóstico - Plan Quito 1980.

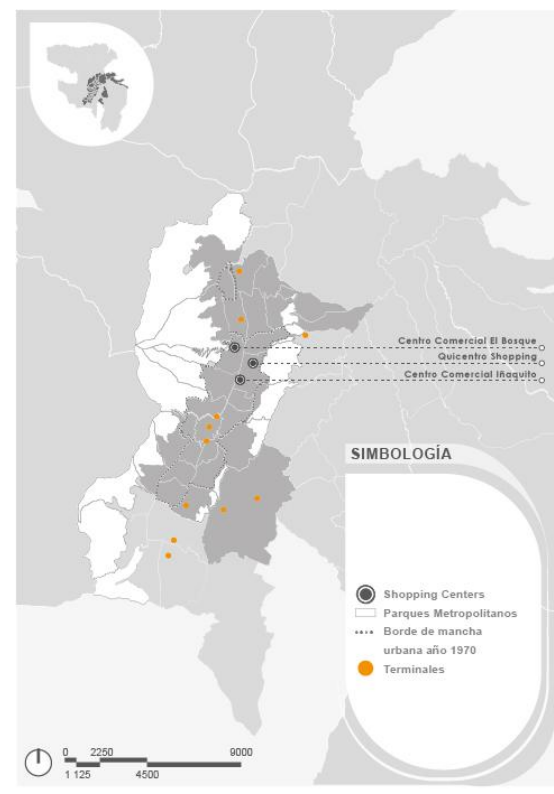

Figura 23. Transporte 1980 - Quito

Fuente: Elaboración propia a partir del Diagnóstico - Plan de Estructura Urbana 1990.

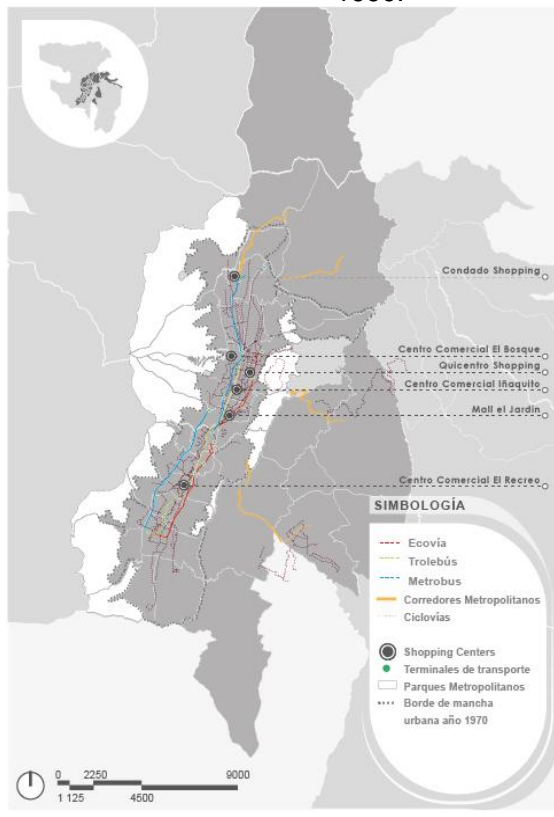

Figura 25. Transporte 2000 - Quito Fuente: Elaboración propia a partir del Diagnóstico - Plan Metropolitano de Ordenamiento Territorial $2012-2022$.

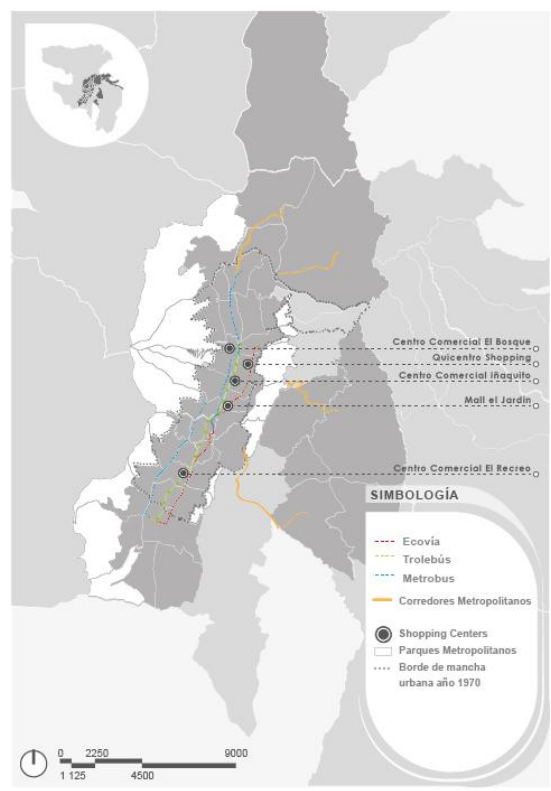

Figura 24. Transporte 1990 - Quito

Fuente: Elaboración propia a partir del Diagnóstico - Plan General de Desarrollo Territorial $2000-2020$.

\section{Figura 26. Transporte 2015 - Quito}

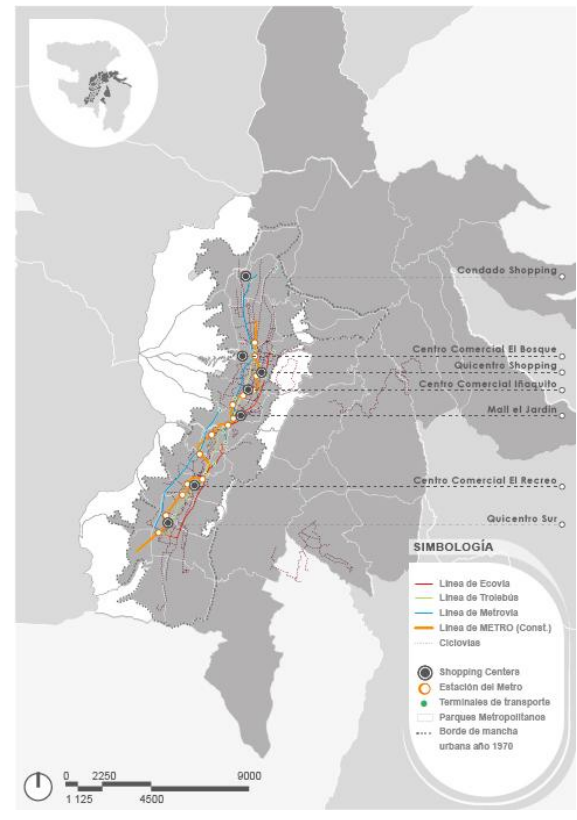

Fuente: Elaboración propia a partir del Diagnóstico - Plan de Desarrollo y de Ordenamiento Territorial, 2015. 
Los sistemas de bus rápido longitudinales o BRT's se construyen en los años 90: línea oriental o Ecovía, línea central o Trolebus y línea occidental o Metrobus, apoyados por corredores metropolitanos que se articulan con el área metropolitana de Quito. En los años 2000 se incorpora una ciclovía recreacional y en el año 2015 se inicia la construcción del Metro de Quito y un circuito de ciclovías equipadas con estaciones de bicicletas públicas destinadas al transporte. Es evidente en el análisis gráfico que los shopping centers están bien abastecidos en relación al acceso al transporte público masivo.

\section{Densidad - Espacio Concebido}

En relación a la densidad poblacional planificada, se puede verificar en las figuras 27, 28, 29, 30 y 31 que los planes proponen incrementarla en el hipercentro del centro norte de Quito y en el hipercentro del centrosur que coincide con la inserción y consolidación de las áreas en torno a los shopping centers.

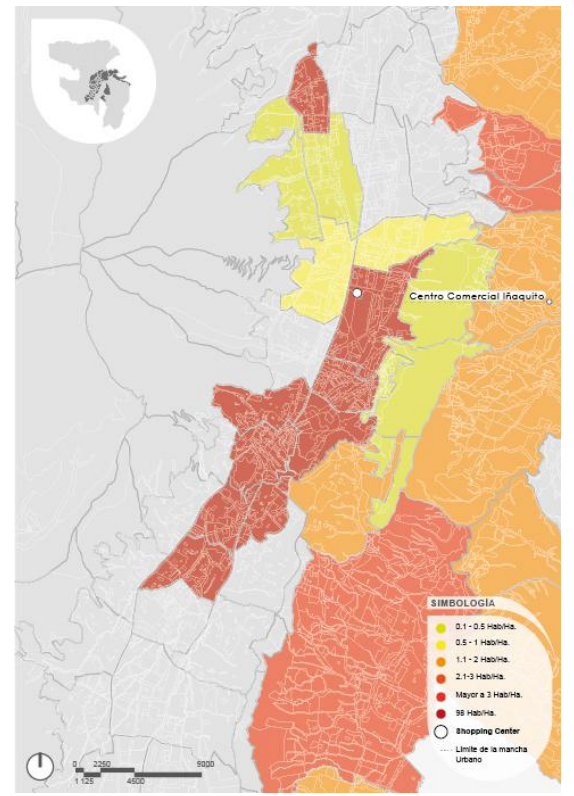

Figura 27. Densidad de población 1970 Quito

Fuente: Elaboración propia a partir Plan Director de Quito 1973 - 1993.

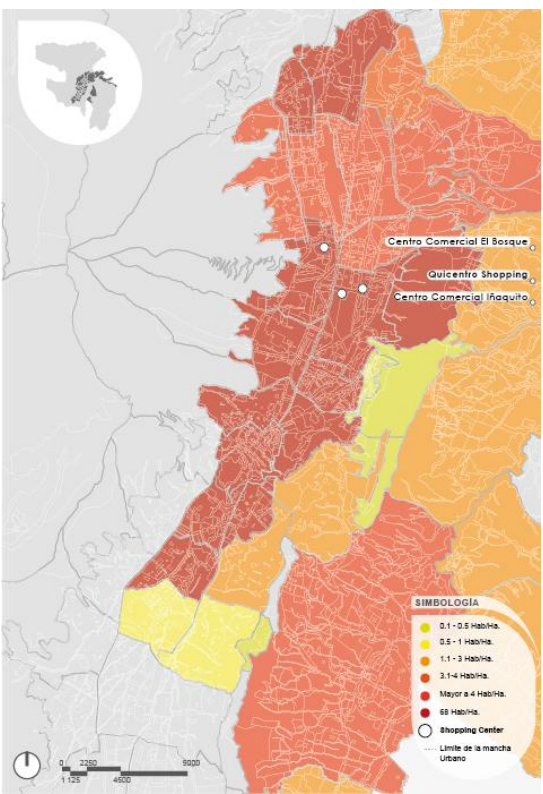

Figura 28. Densidad de población 1980 Quito

Fuente: Elaboración propia a partir Plan Quito 1980.

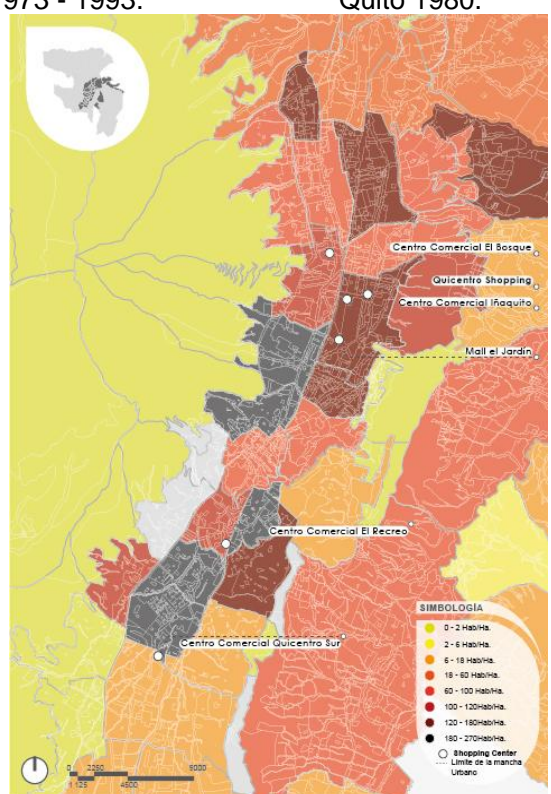

Figura 30. Densidad de población 2000 . Quito

Fuente: Elaboración propia a partir del Plan General de Desarrollo Territorial 2000 - 2020.

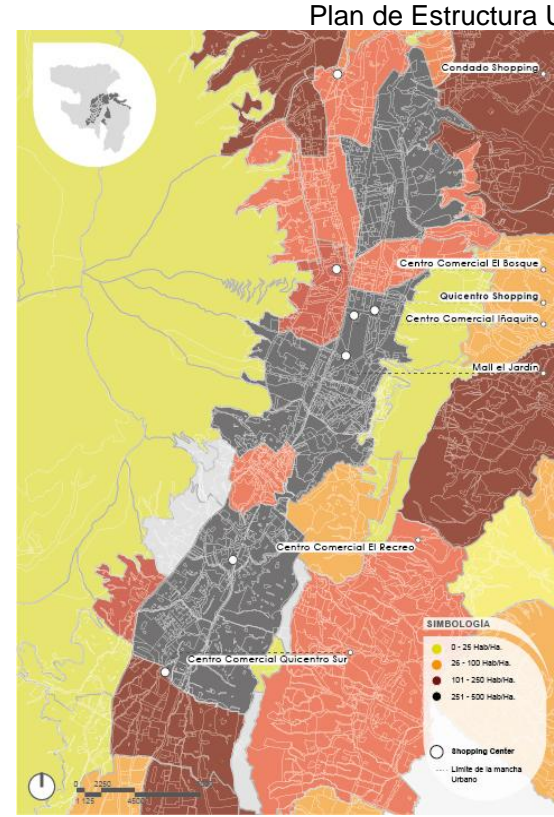

Figura 31. Densidad de población 2015 Quito

Fuente: Elaboración propia a partir del Plan de Desarrollo y de Ordenamiento Territorial, 2015. 


\section{Densidad - Espacio Percibido}

En relación a la densidad poblacional, se puede verificar en las figuras 32, 33, 34, 35 y 36 que ésta aumenta en el hipercentro norte y en el hipercentro sur y coincide con la inserción de los shoppings centers en la ciudad.
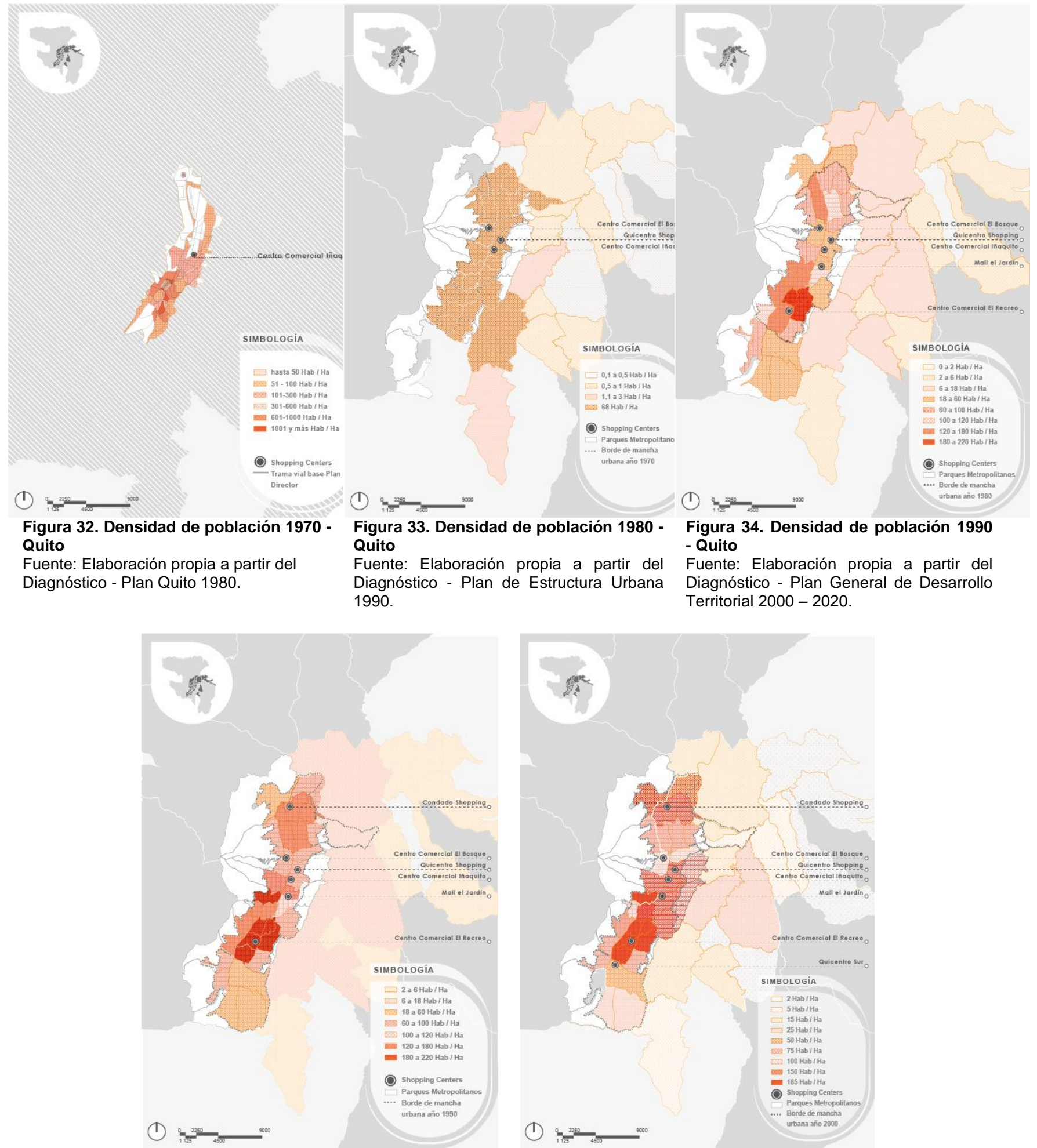

Figura 35. Densidad de población 2000 Quito

Figura 36. Densidad de población 2015 - Quito

Fuente: Elaboración propia a partir del

Diagnóstico - Plan Metropolitano de Ordenamiento Territorial $2012-2022$.

Fuente: Elaboración propia a partir del Diagnóstico - Plan de Desarrollo y de Ordenamiento Territorial, 2015. 
En esta escala es importante resaltar que a partir de la planificación, el territorio se "prepara" para una posible inserción de shopping centers a partir de la planificación de centros consolidados con uso de suelo múltiple, equipamientos, accesibilidad con transporte público y con un incremento de la densidad poblacional. También es importante verificar que con la efectiva inserción de los shopping centers, los hipercentros planteados se fortalecen y se convierten en piezas urbanas con un alto grado de centralidad evidenciada por la concentración de uso de suelo múltiple, de equipamientos y espacios públicos, de densidad y de transporte.

\subsection{Espacio Concebido y Percibido del Quicentro Shopping center - Escala Sector de Iñaquito}

En esta escala, y desde el espacio concebido y percibido, se busca realizar un análisis gráfico de la planificación y de la efectiva materialización del sector de Iñaquito (donde está emplazado el Quicentro Shopping Center (y otros) en relación a la inserción de shopping centers.

\section{Uso de Suelo - Espacio Concebido}

En las figuras $37,38,39,40$ y 41 se puede observar el uso de suelo planteado por los planes de ordenamiento territorial desde el año de 1970 hasta el del 2015.

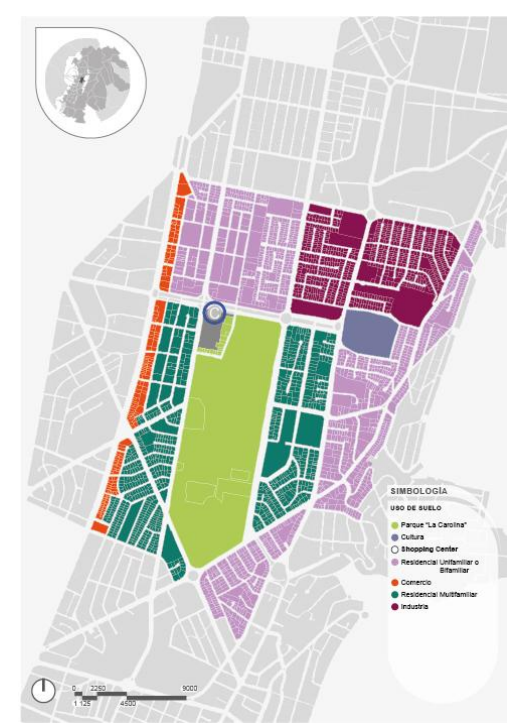

Figura 37. Uso de suelo 1970 - Quito Fuente: Elaboración propia a partir Plan Director de Quito 1973 - 1993.

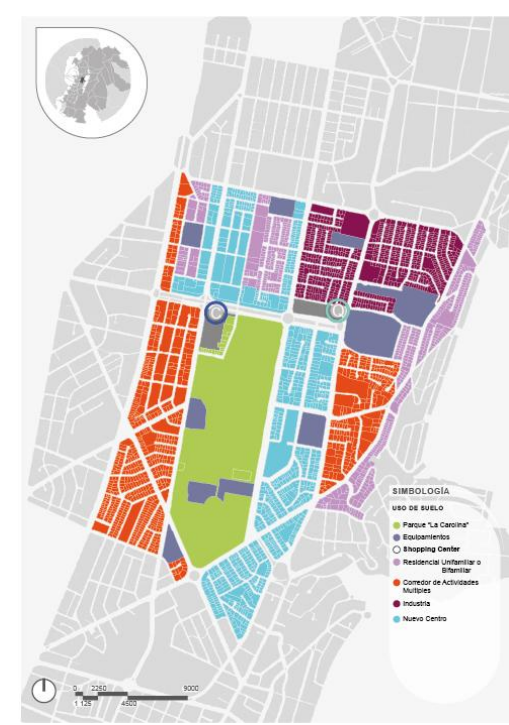

Figura 38. Uso de suelo 1980 - Quito Fuente: Elaboración propia a partir Plan Quito 1980.

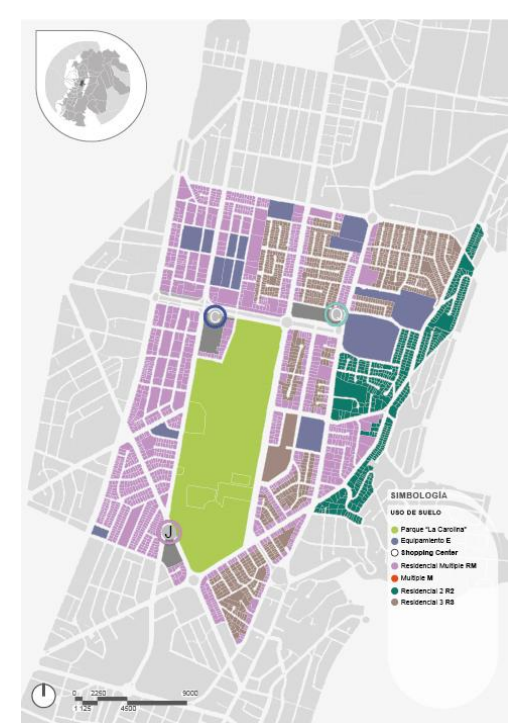

Figura 39. Uso de suelo 1990 - Quito Fuente: Elaboración propia a partir del Plan de Estructura Urbana 1990.

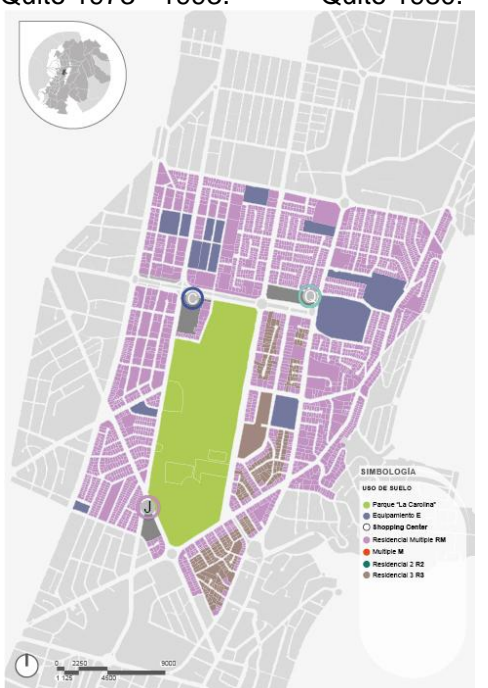

Figura 40. Uso de suelo 2000 - Quito Fuente: Elaboración propia a partir del Plan General de Desarrollo Territorial 2000 2020.

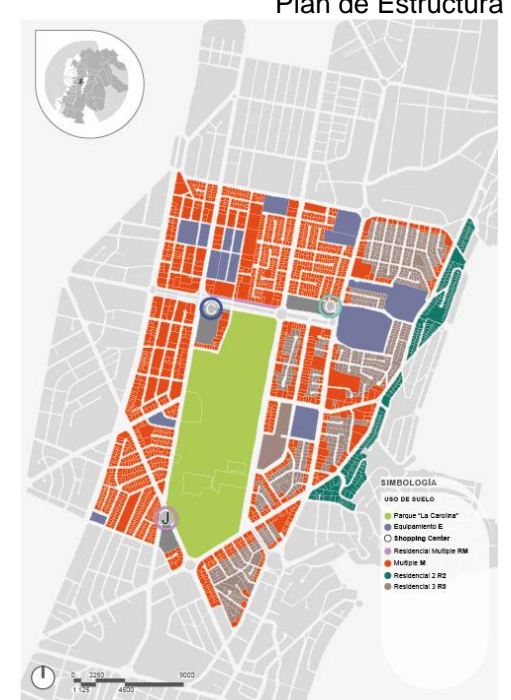

Figura 41. Uso de suelo 2015 - Quito Fuente: Elaboración propia a partir del Plan de Desarrollo y de Ordenamiento Territorial, 2015. 
Se puede observar que conforme pasa el tiempo se plantea un incremento en el uso de suelo múltiple y de equipamientos en el sector. En los años 70 se propuso que el terreno del Quicentro Shopping Center y su entorno norte sea un área industrial de bajo impacto, sin embargo se consolidó como un área residencial de baja densidad en la misma década, y ya para el año de 1980 se planificó el sector como un área residencial sin compatibilidad con el comercio. En los años 90, posterior a la construcción del QSC (1982) se permite el uso comercial en escala local (Residencial 3). Ya desde el año 2000 se propone el uso de suelo residencial múltiple que permite el comercio en escala barrial, y en el año 2015 se posibilita el uso de suelo múltiple en torno al Quicentro shopping center. Así, se evidencia el incremento del uso de suelo múltiple desde la planificación territorial en escala del Sector.

\section{Uso de Suelo - Espacio Percibido}

En las figuras $42,43,44,45$ y 46 se puede observar las efectivas transformaciones del uso de suelo en el sector de Iñaquito. Se verifica que conforme pasa el tiempo, el uso de suelo múltiple incrementa al igual que el número de equipamientos. Es importante resaltar que el uso de suelo residencial múltiple apareció previo al plan pero que en el 2015 el uso de suelo múltiple aún no alcanza el grado de concentración planificado. Sin embargo se evidencia un patrón de incremento del uso de suelo múltiple en torno a los shopping centers.

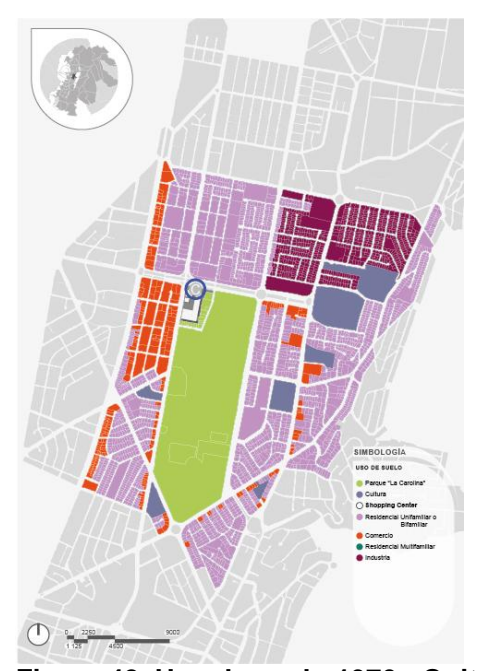

Figura 42. Uso de suelo 1970 - Quito Fuente: Elaboración propia a partir del Diagnóstico - Plan Quito 1980.

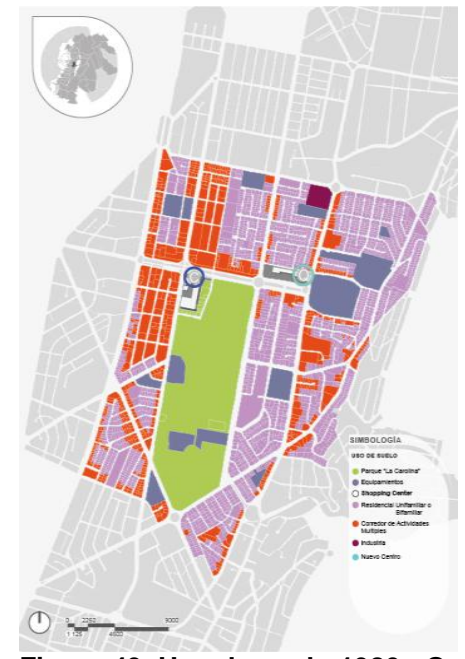

Figura 43. Uso de suelo 1980 - Quito Fuente: Elaboración propia a partir del Diagnóstico - Plan de Estructura Urbana 1990.

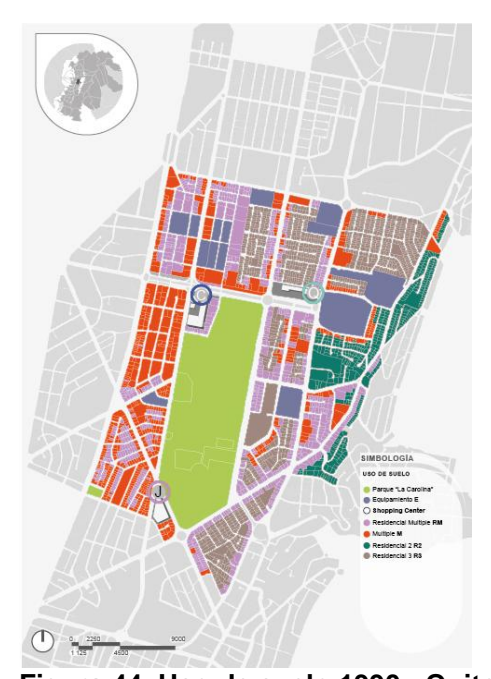

Figura 44. Uso de suelo 1990 - Quito Fuente: Elaboración propia a partir del Diagnóstico - Plan General de Desarrollo Territorial $2000-2020$

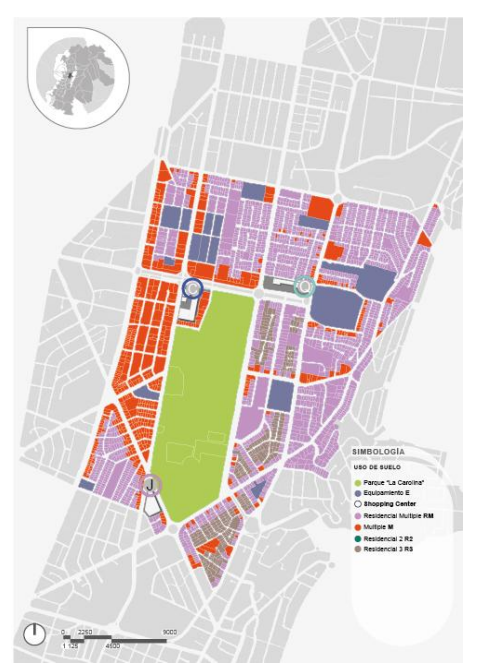

Figura 45. Uso de suelo 2000 - Quito Fuente: Elaboración propia a partir del Diagnóstico - Plan Metropolitano de Ordenamiento Territorial $2012-2022$.

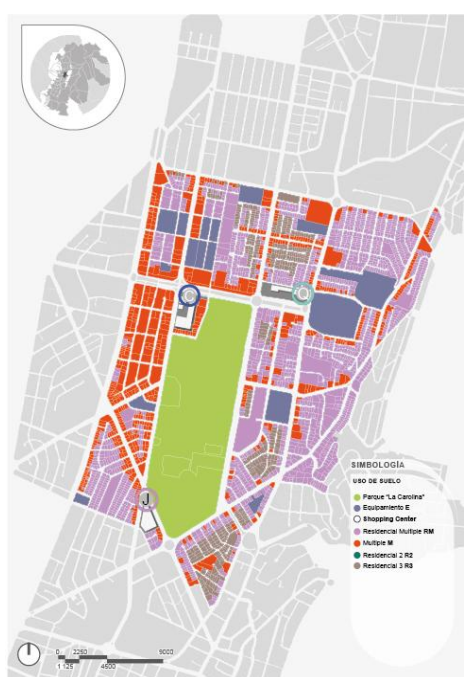

Figura 46. Uso de suelo 2015 - Quito Fuente: Elaboración propia a partir del Diagnóstico - Plan de Desarrollo y de Ordenamiento Territorial, 2015. 


\section{Transporte - Espacio Concebido}

En las figuras 47, 48, 49, 50 y 51 se puede observar la propuesta de articulación del sector con diferentes medios de transporte público masivo como BRT's (Ecovía, Trolebus y Metrobus), metro y ciclovías. Es decir, desde la planificación se busca abastecer a este hipercentro con diferentes medios de transporte que abastezcan el ingreso, la salida y el movimiento interno del sector.

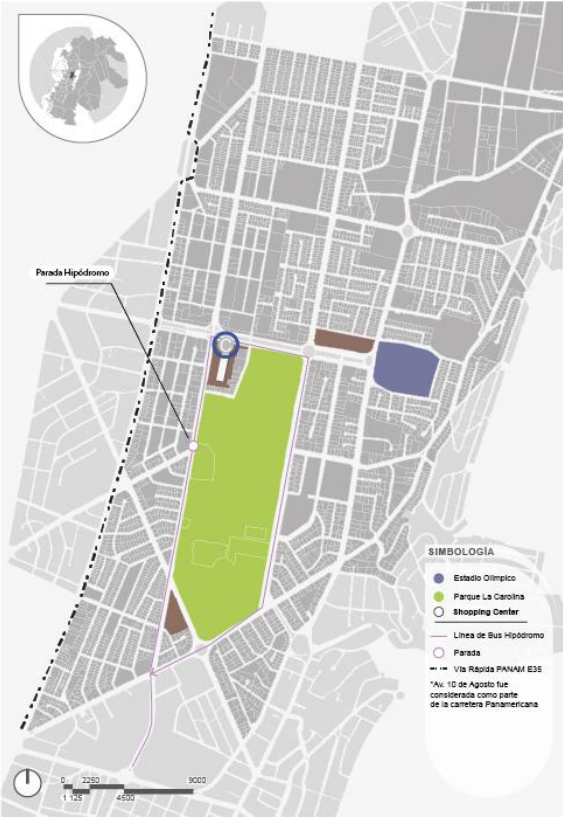

Figura 47. Transporte 1970 - Quito

Fuente: Elaboración propia a partir Plan Director de Quito 1973 - 1993.

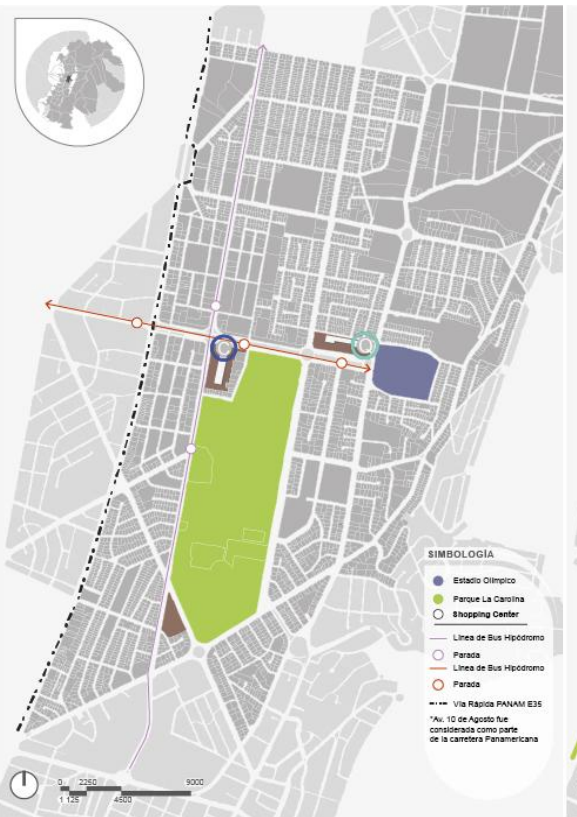

Figura 48. Transporte 1980 - Quito

Fuente: Elaboración propia a partir Plan Quito 1980.

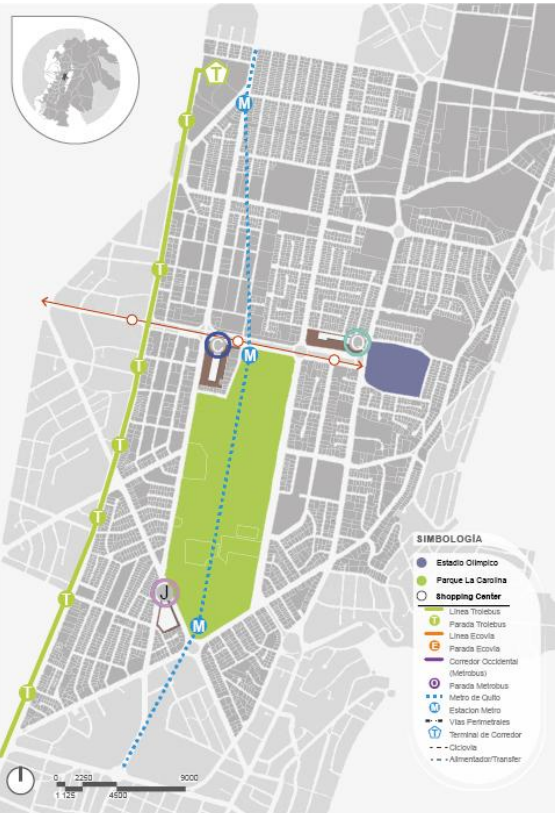

Figura 49. Transporte 1990 - Quito

Fuente: Elaboración propia a partir del Plan de Estructura Urbana 1990.

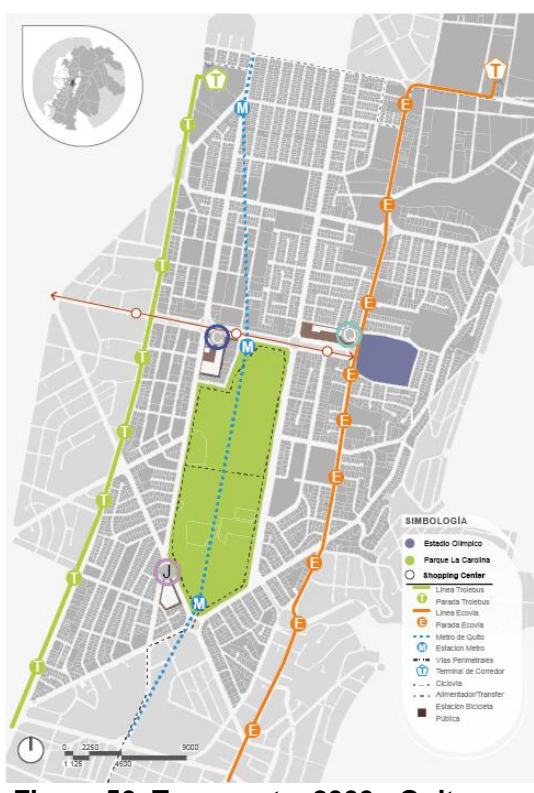

Figura 50. Transporte 2000 - Quito Fuente: Elaboración propia a partir del Plan General de Desarrollo Territorial 2000 - 2020.

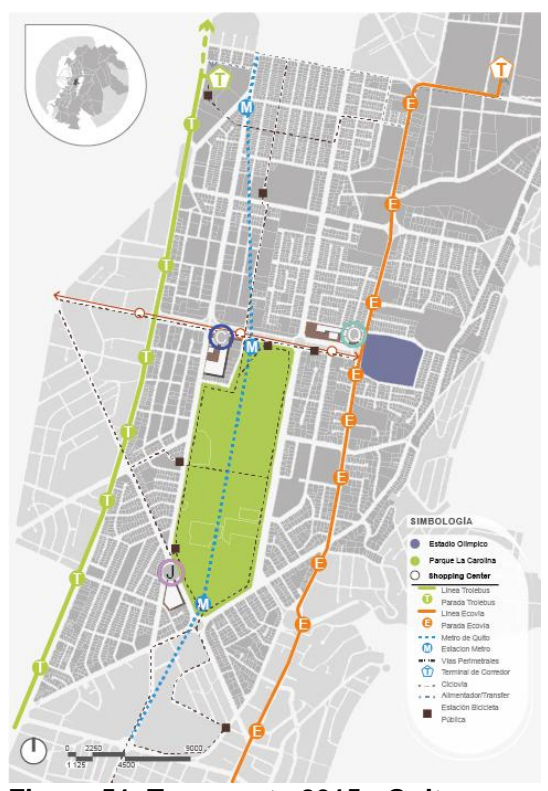

Figura 51. Transporte 2015 - Quito

Fuente: Elaboración propia a partir del Plan de Desarrollo y de Ordenamiento Territorial, 2015.

\section{Transporte - Espacio Percibido}

En las figura 52, 53, 54, 55 y 56 se evidencia la efectiva articulación del sector con diferentes medios de transporte, incluso más circuitos de ciclovías de las que fueron planificadas. En el 2015 empezaron las obras de construcción de las paradas de metro de quito en el sector. 


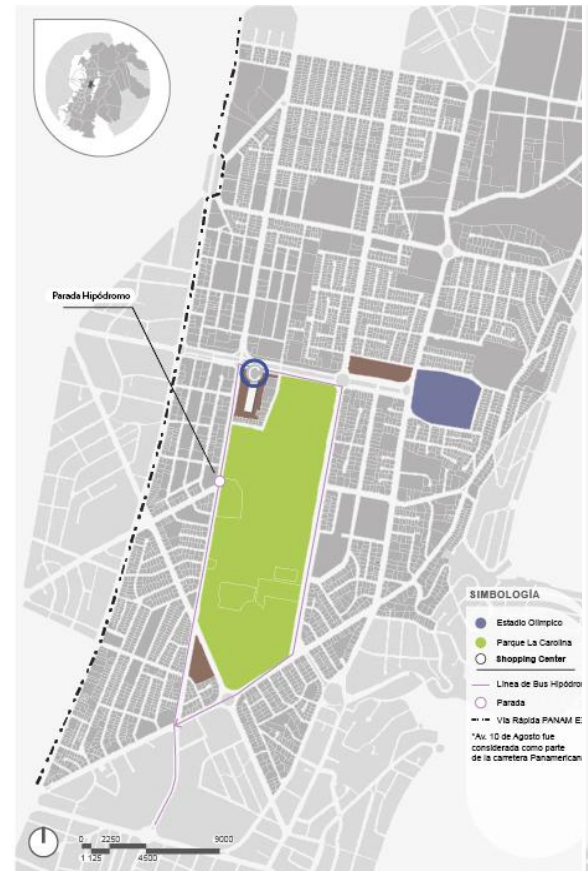

Figura 52. Transporte 1970 - Quito Fuente: Elaboración propia a partir del Diagnóstico - Plan Quito 1980.

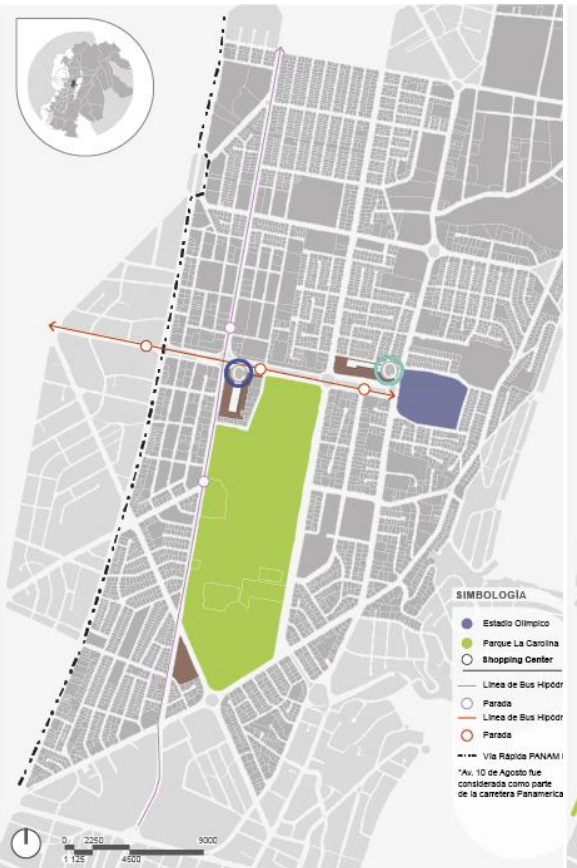

Figura 53. Transporte 1980 - Quito Fuente: Elaboración propia a partir del Diagnóstico - Plan de Estructura Urbana 1990.

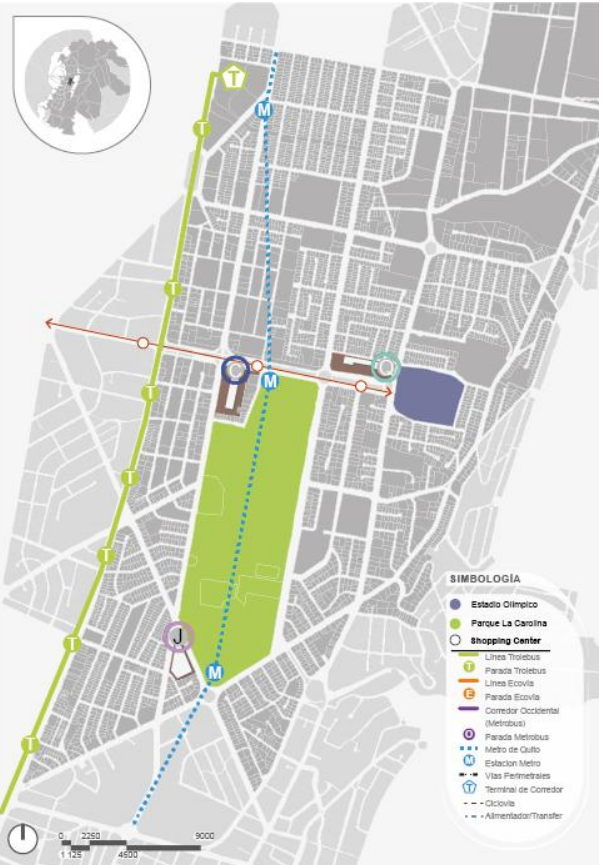

Figura 54. Transporte 1990 - Quito

Fuente: Elaboración propia a partir del Diagnóstico - Plan General de Desarrollo Territorial $2000-2020$.

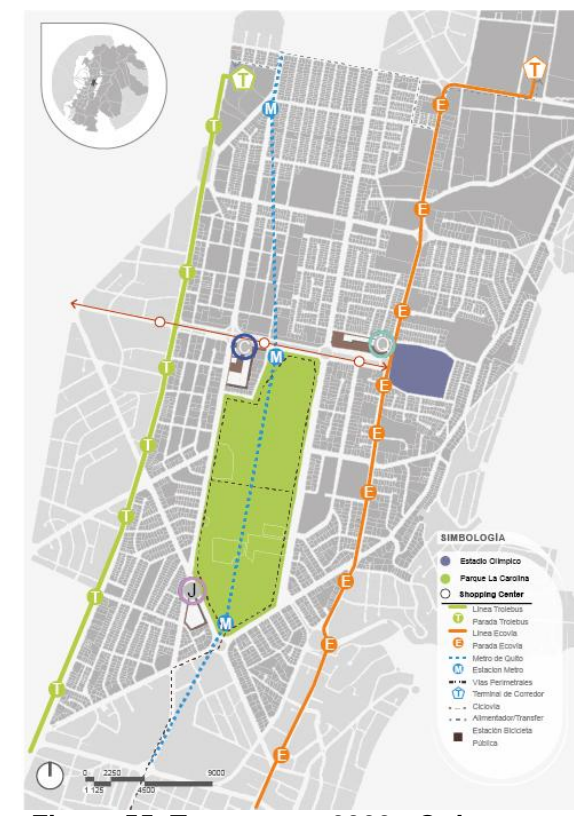

Figura 55. Transporte 2000 - Quito

Fuente: Elaboración propia a partir de Diagnóstico - Plan Metropolitano de Ordenamiento Territorial 2012 - 2022.

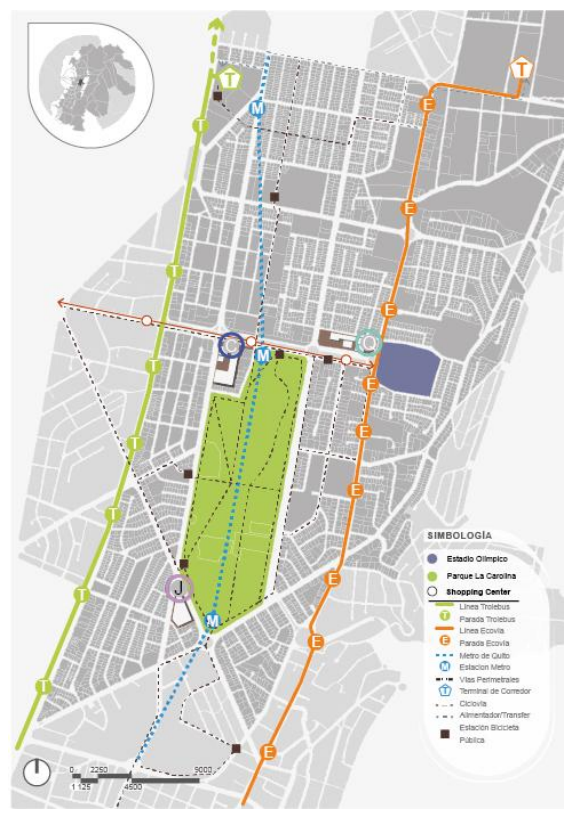

Figura 56. Transporte 2015 - Quito

Fuente: Elaboración propia a partir del Diagnóstico - Plan de Desarrollo y de Ordenamiento Territorial, 2015.

\section{Densidad - Espacio Concebido}

En relación a la densidad poblacional planificada, se puede observar en las figuras $57,58,59,60$ y 61 que se propone un claro incremento de densidad en el sector. Es importante resaltar que también se propone una modificación del microparcelamiento (lotes) y que se transforman a los lotes de mayor tamaño en áreas destinadas a la construcción de equipamientos. 


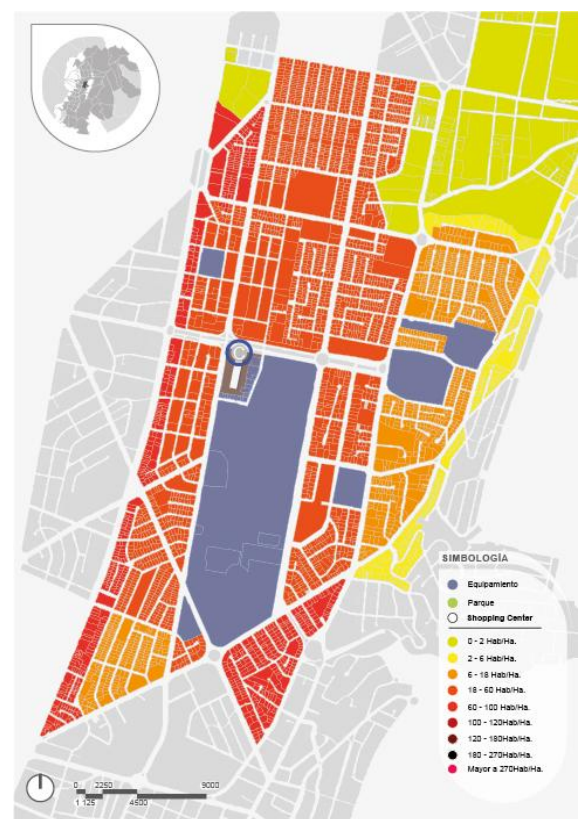

Figura 57. Densidad de población 1970 - Quito

Fuente: Elaboración propia a partir Plan Director de Quito 1973 - 1993.

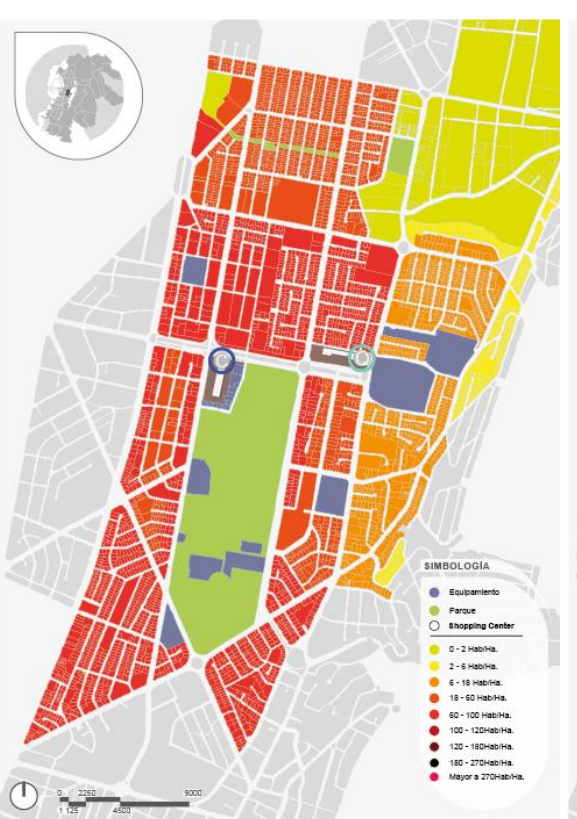

Figura 58. Densidad de población 1980 Quito

Fuente: Elaboración propia a partir Plan Quito 1980.

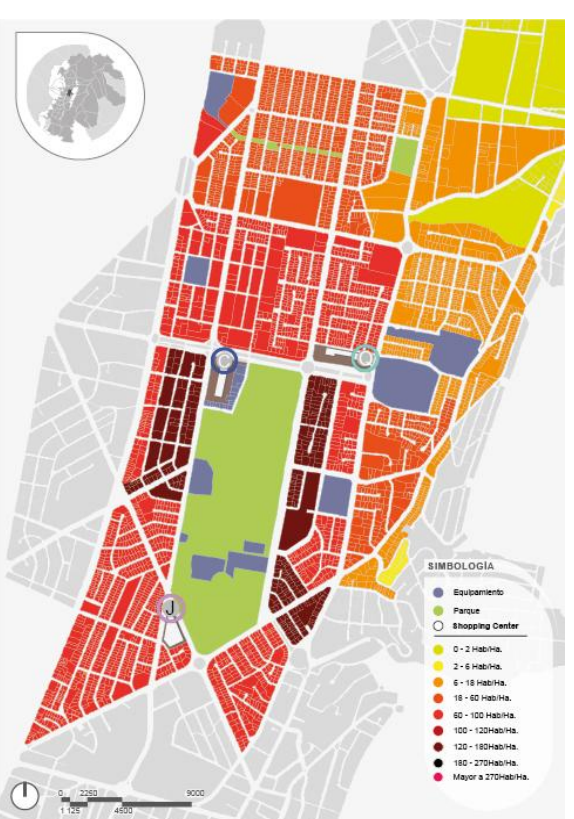

Figura 59. Densidad de población 1990 Quito

Fuente: Elaboración propia a partir del Plan de Estructura Urbana 1990.

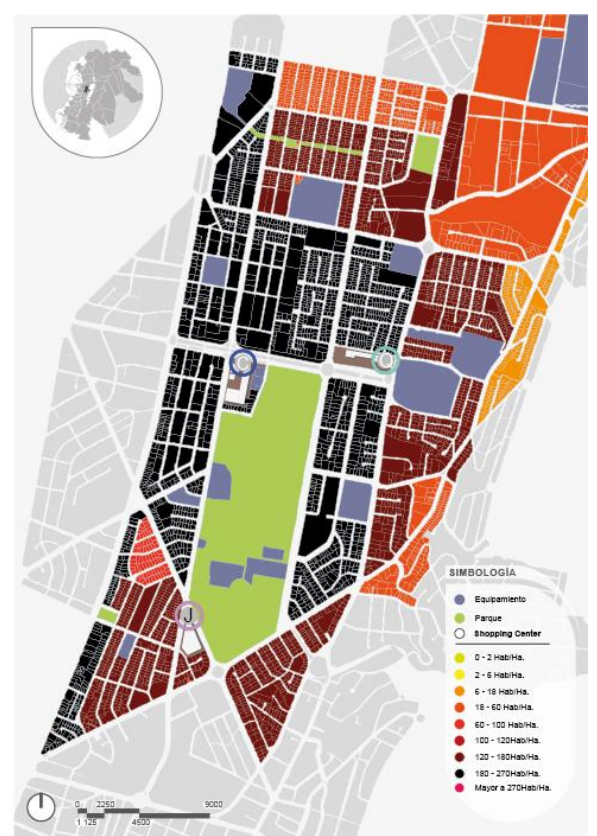

Figura 60. Densidad de población 2000 Quito

Fuente: Elaboración propia a partir del Plan General de Desarrollo Territorial 2000 - 2020.

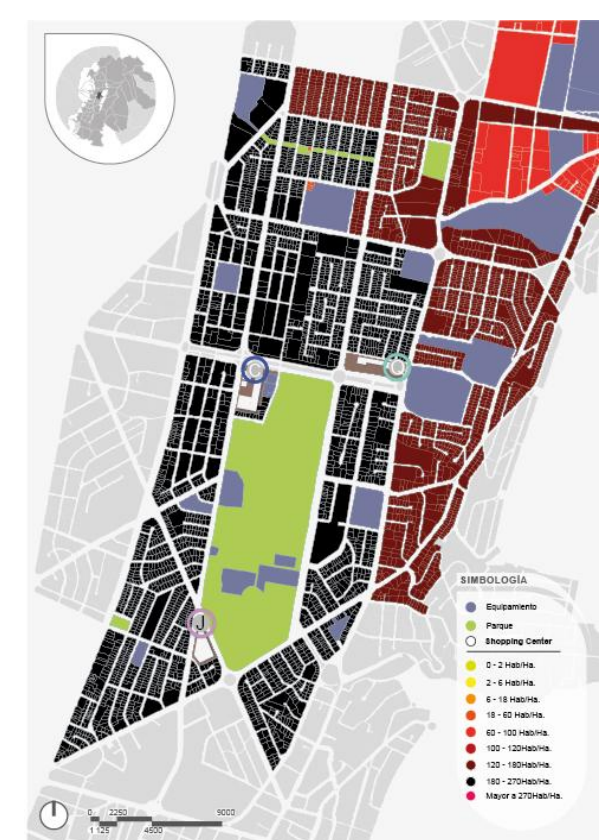

Figura 61. Densidad de población 2015 Quito

Fuente: Elaboración propia a partir del Plan de Desarrollo y de Ordenamiento Territorial, 2015.

\section{Densidad - Espacio Percibido}

En relación a la efectiva densidad poblacional, se puede verificar en las figuras 62, 63, 64, 65 y 66 que la densidad ha incrementado, incluso a mayor velocidad y en mayor cantidad que concebida en los planes de ordenamiento territorial. Es importante observar que los lotes modificados en los planes fueron efectivamente modificados y transformados en equipamientos del sector. 


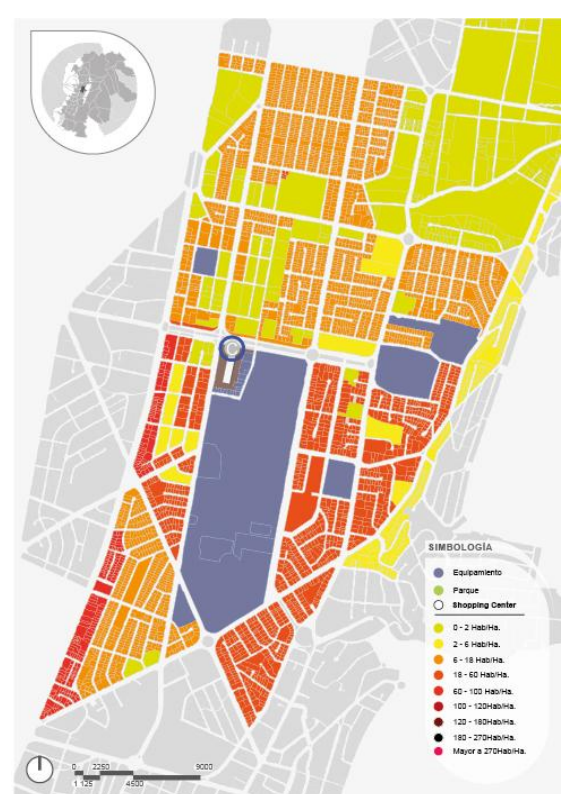

Figura 62. Densidad de población 1970 - Quito

Fuente: Elaboración propia a partir del Diagnóstico - Plan Quito 1980.

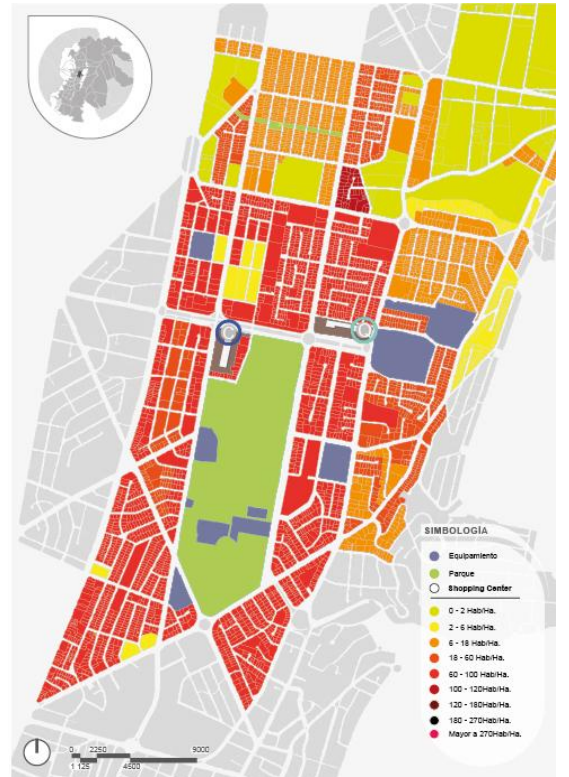

Figura 63. Densidad de población 1980 . Quito

Fuente: Elaboración propia a partir de Diagnóstico - Plan de Estructura Urbana 1990.

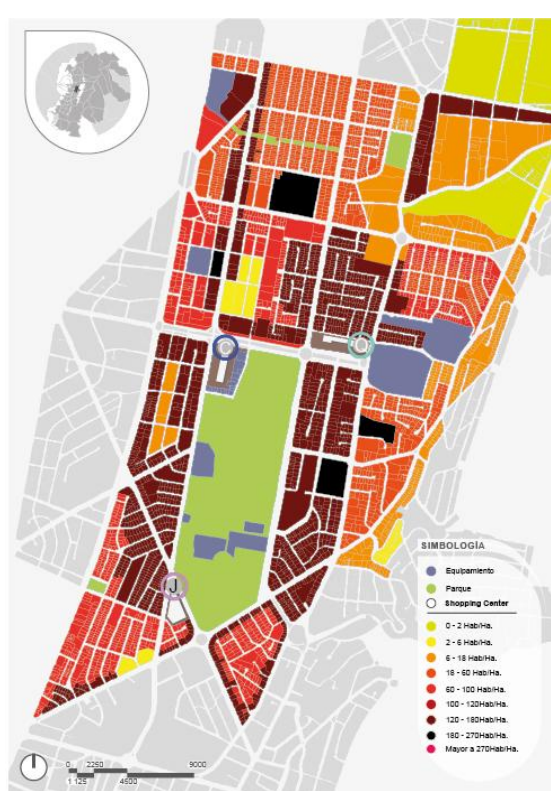

Figura 64. Densidad de población 1990 - Quito

Fuente: Elaboración propia a partir del Diagnóstico - Plan General de Desarrollo Territorial $2000-2020$.

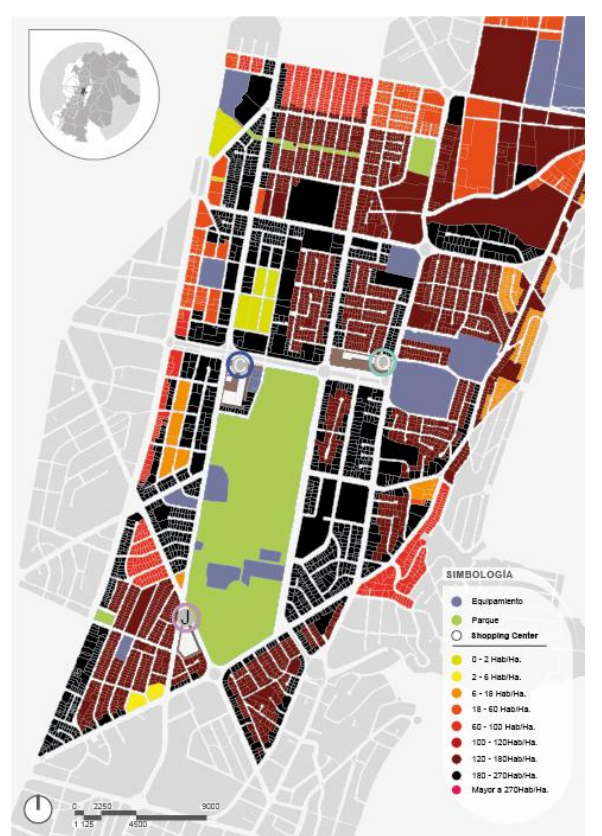

Figura 65. Densidad de población 2000 Quito

Fuente: Elaboración propia a partir del Diagnóstico - Plan Metropolitano de Ordenamiento Territorial 2012 - 2022.

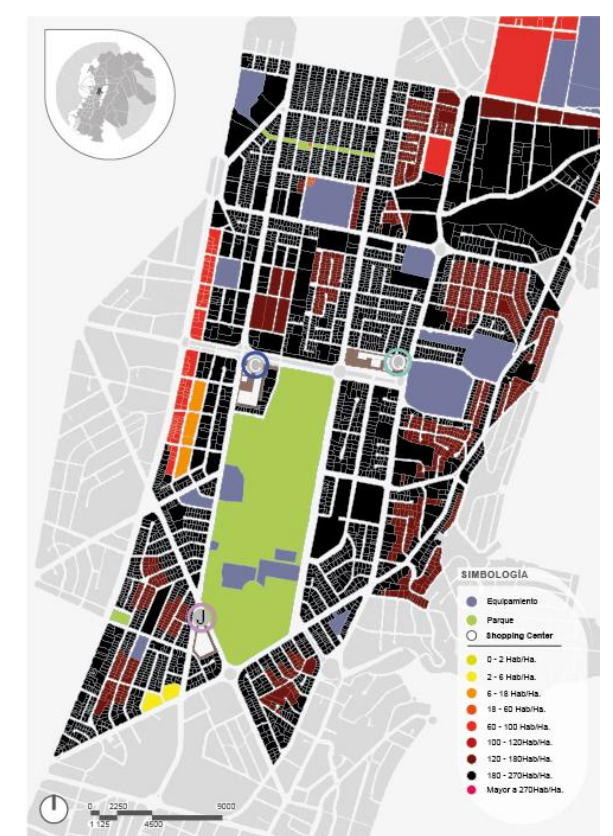

Figura 66. Densidad de población 2015 Quito

Fuente: Elaboración propia a partir de Diagnóstico - Plan de Desarrollo y de Ordenamiento Territorial, 2015.

\section{Zonificación/Edificabilidad - Espacio Concebido}

En relación a la zonificación planificada, se puede observar en las figuras $67,68,69,70$ y 71 que se ha planificado el incremento de pisos en todo el sector. En la zona más próxima al QSC se plantea el mayor incremento que alcanza hasta los 12 pisos. La forma de ocupación de los lotes se ha mantenido en aislada durante todo el período analizado. 


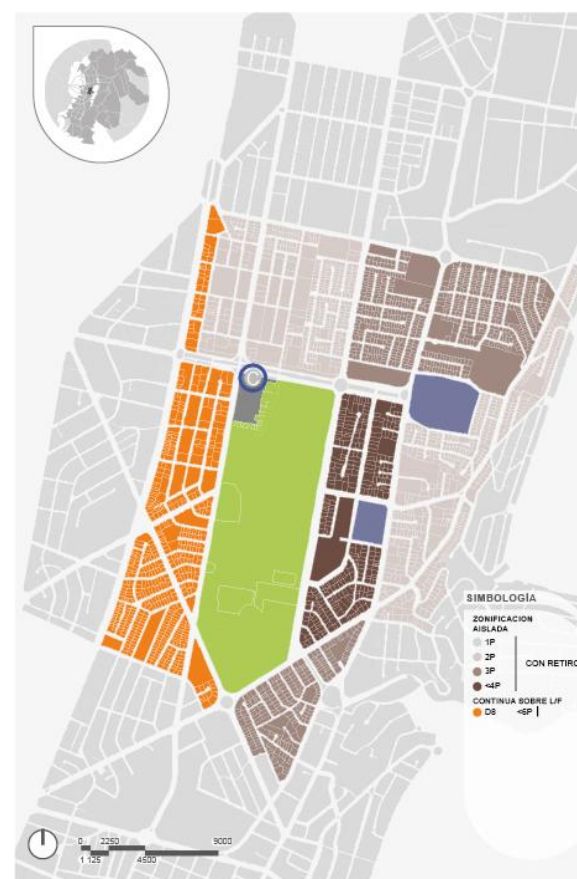

Figura 67. Edificabilidad 1970 - Quito Fuente: Elaboración propia a partir Plan Director de Quito 1973 - 1993.

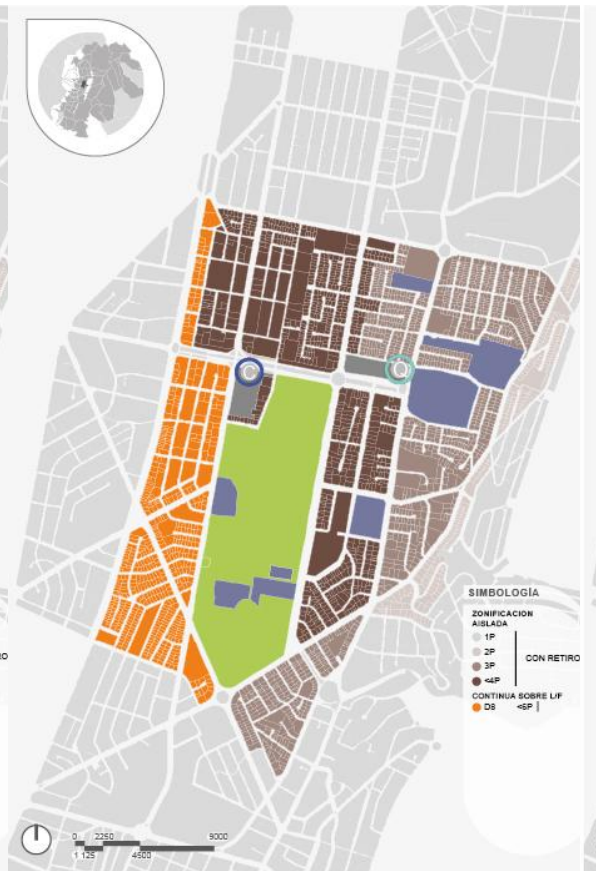

Figura 68. Edificabilidad 1980 - Quito Fuente: Elaboración propia a partir Plan Quito 1980.

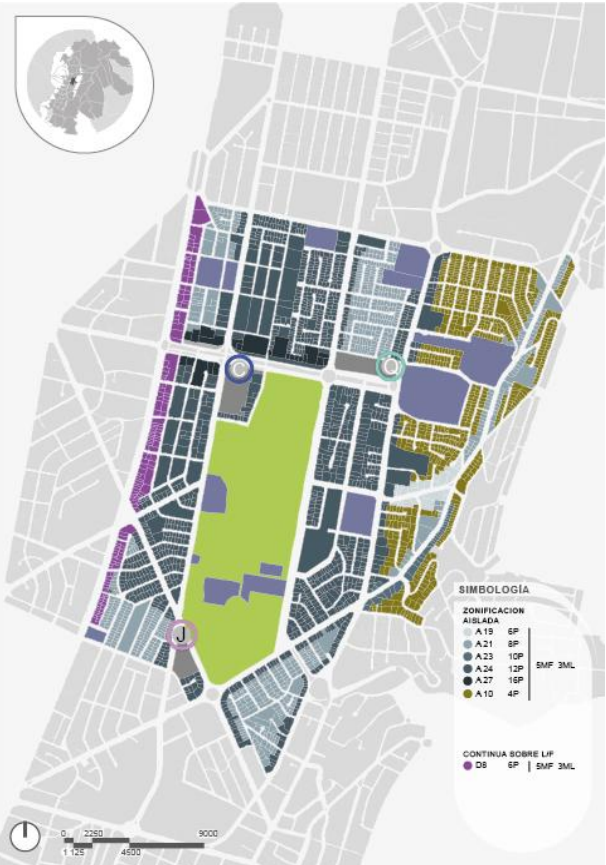

Figura 69. Edificabilidad 1990 - Quito Fuente: Elaboración propia a partir del Plan de Estructura Urbana 1990.

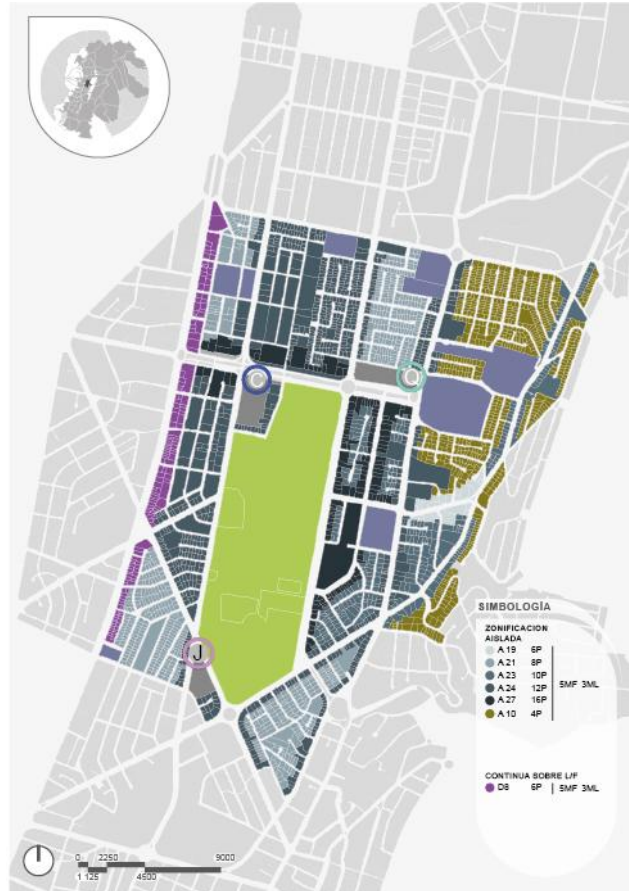

Figura 70. Edificabilidad 2000 - Quito

Fuente: Elaboración propia a partir del Plan General de Desarrollo Territorial 2000 - 2020.

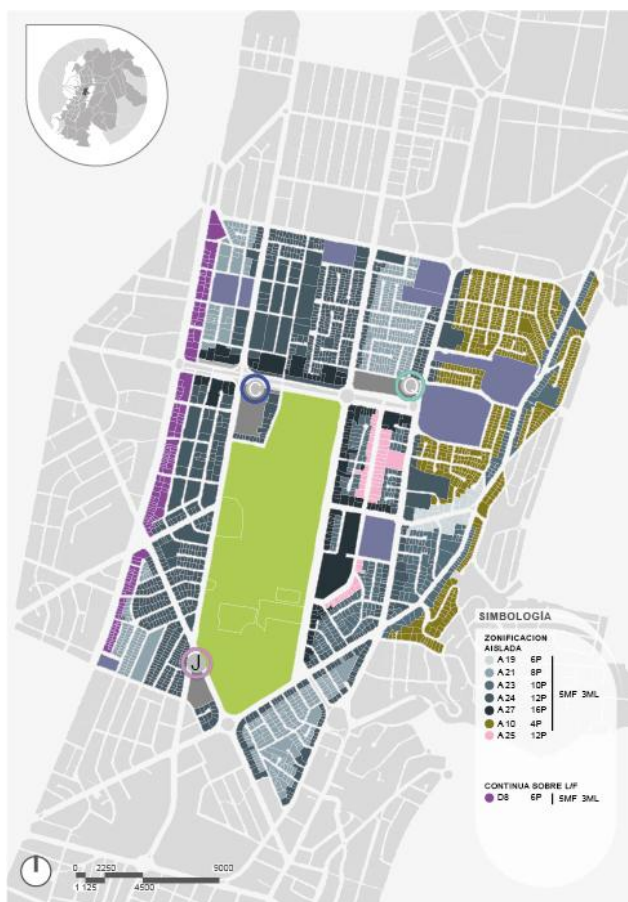

Figura 71. Edificabilidad 2015 - Quito

Fuente: Elaboración propia a partir del Plan de Desarrollo y de Ordenamiento Territorial, 2015.

\section{Zonificación y Edificabilidad - Espacio Percibido}

En relación a la efectiva edificabilidad y zonificación, en las figuras $72,73,74,75$ y 76 se evidencia que el número de pisos no ha incrementado como fue propuesto en el plan, sin embargo la densidad poblacional ha aumentado. Es importante resaltar que los edificios más altos están localizados en torno al Quicentro Shopping Center. 


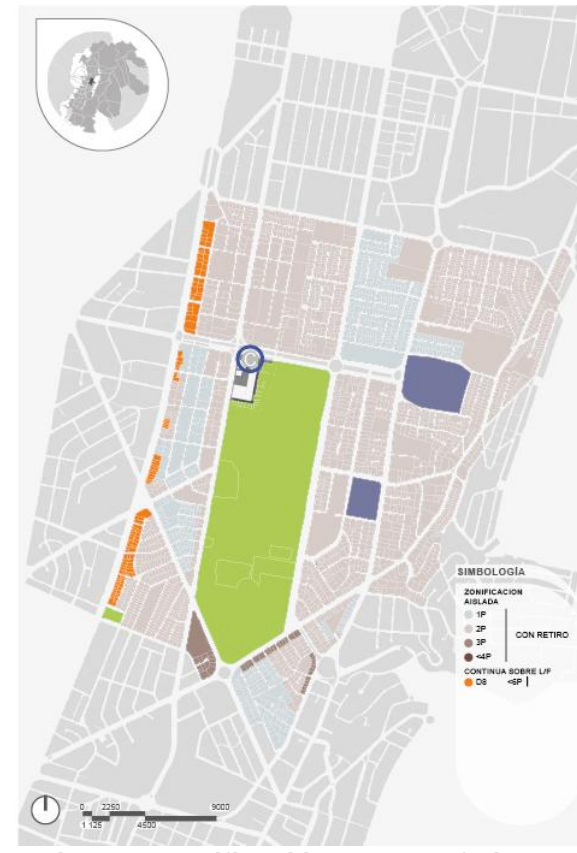

Figura 72. Edificabilidad 1970 - Quito Fuente: Elaboración propia a partir del Diagnóstico - Plan Quito 1980.

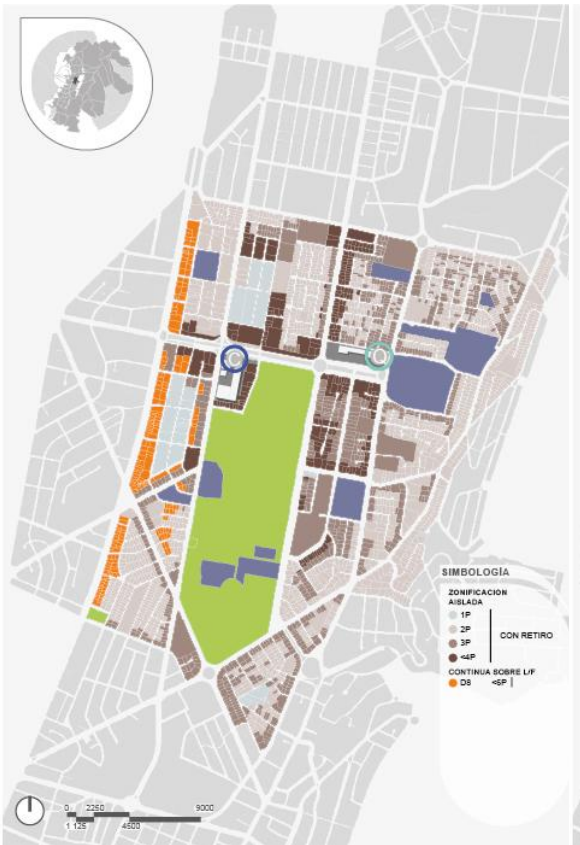

Figura 73. Edificabilidad 1980 - Quito

Fuente: Elaboración propia a partir del Diagnóstico - Plan de Estructura Urbana 1990.

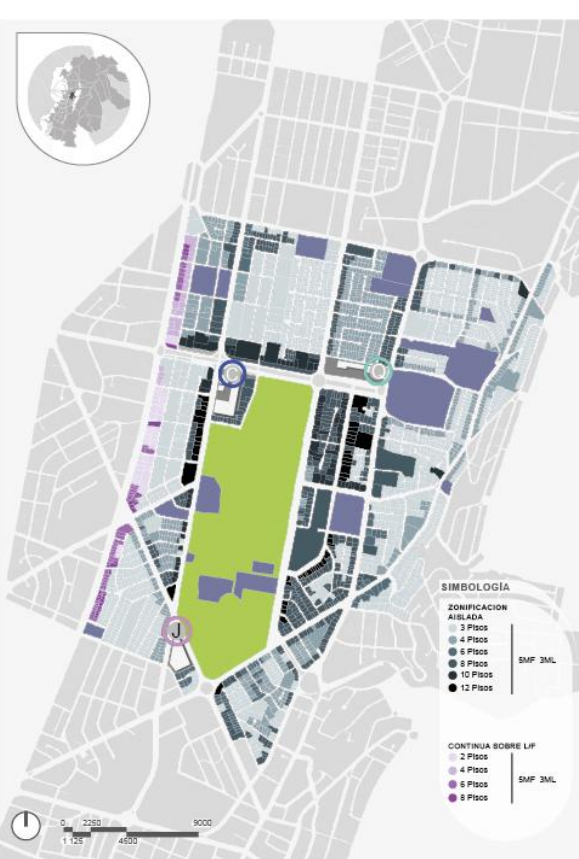

Figura 74. Edificabilidad 1990 - Quito

Fuente: Elaboración propia a partir del Diagnóstico - Plan General de Desarrollo Territorial $2000-2020$.

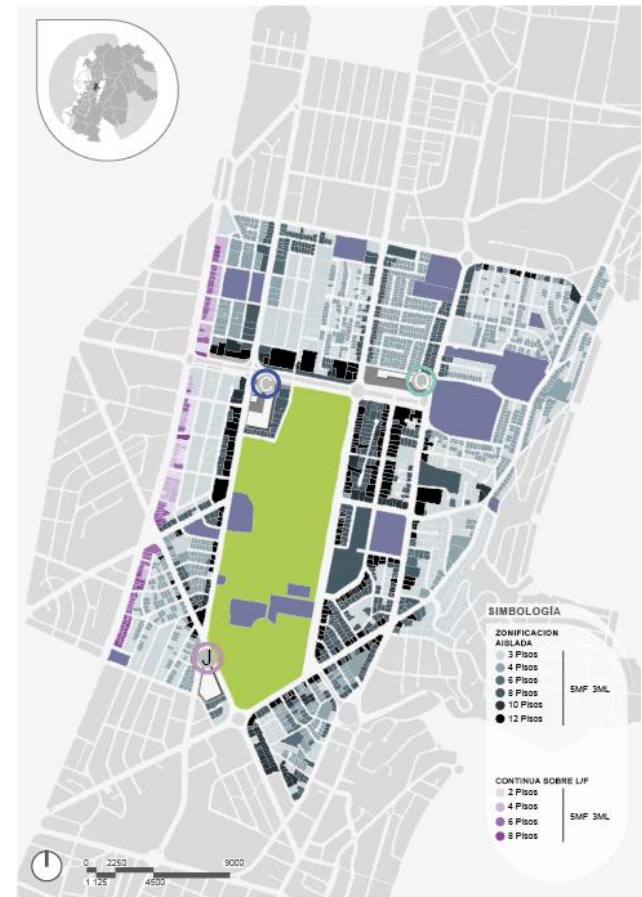

Figura 75. Edificabilidad 2000 - Quito

Fuente: Elaboración propia a partir del Diagnóstico - Plan Metropolitano de Ordenamiento Territorial $2012-2022$.

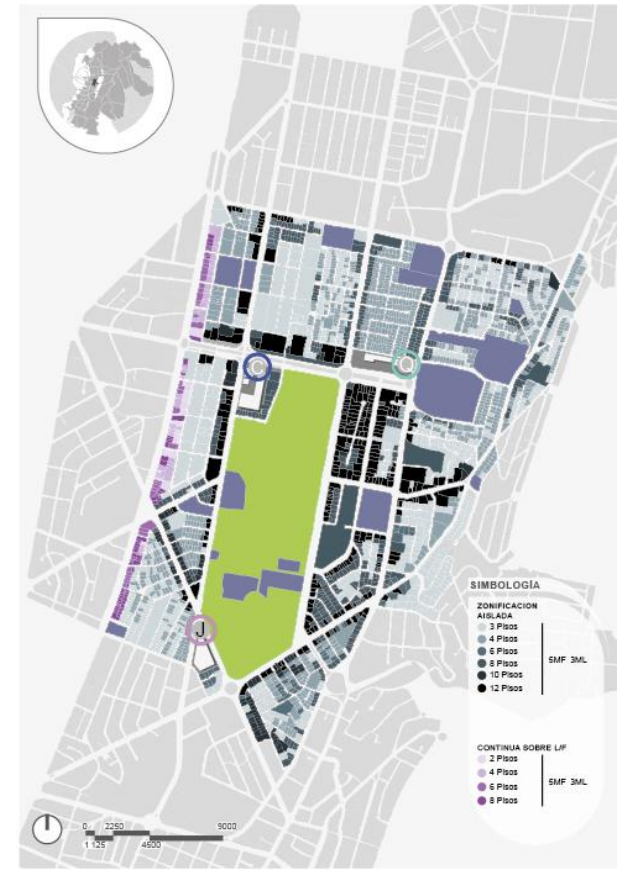

Figura 76. Edificabilidad 2015 - Quito

Fuente: Elaboración propia a partir del Diagnóstico - Plan de Desarrollo y de Ordenamiento Territorial, 2015. 


\section{CONSIDERACIONES FINALES}

Después de realizar esta investigación, y evidenciar los resultados, se considera fundamental realizar un análisis profundo de cada shopping center con su especificidad geográfica, cultural, política, social y económica, puesto que analizarlos de forma genérica sería impreciso y poco objetivo.

Se pudo observar que desde la planificación de Quito, el territorio "prepara" las condiciones óptimas para una posterior inserción de un shopping center, sin querer decir con esto que los shopping centers sean planificados desde las administraciones locales. Los terrenos donde han sido insertados los shopping centers fueron concebidos como terrenos para equipamientos que abastezcan a la ciudad y al sector.

Se pudo observar que las áreas en torno a los shopping centers de Quito no han "muerto", al contrario, la concentración de uso de suelo múltiple, la densidad poblacional, el acceso a transporte público masivo y la edificabilidad ponen en evidencia un alto grado de centralidad en su entorno.

Aunque los shopping centers sean asociados con el consumo de masas y con la materialización de la economía neoliberal, es importante resaltar que su éxito se ha fundamentado en la habilidad de los promotores, quienes han sabido identificar las efectivas necesidades de los usuarios. Estas lógicas resultan interesantes, puesto que los shopping centers podrían ser utilizados (especulando) como instrumentos de planificación y reactivación urbana.

Es evidente en este artículo que el grado de centralidad de las zonas planificadas y construidas puede ser medible y cuantificable en las dos escalas de análisis.

En el contexto académico, es importante realizar un estudio y análisis profundos de estas arquitecturas, despojado de prejuicios ideológicos y políticos. El fenómeno shopping center no debe ser criticado de una forma subjetiva y estigmatizada puesto que los datos evidencian y recalcan datos contrarios a esta corriente de aproximación.

Las planificación y la construcción de la ciudad, analizadas en relación a la inserción del Quicentro shopping center evidencia coincidencias entre las transformaciones morfológicas y reordenamiento de usos, previos y posteriores a su construcción. Sin embargo es importante considerar un equipo multidisciplinar para poder afirmar o negar la influencia real de esta arquitectura en la ciudad.

Este artículo, busca ser una contribución al discurso y a la narrativa académica que aporte al estudio de este apasionante fenómeno que es el shopping center.

\section{BIBLIOGRAFIA}

ABAZA,M (2001) Shopping malls,consumer culture, and the reshaping of public space in Egypt. En Theory, Culture \& Society 18, 5, (97-122) London: Sage, Publications (DOI: 10.1177/02632760122051986)

ANTHONY, H. (1985). The shopping mall: A teenage hangout. En Adolescence 20, 78 (Summer) (307-312). San Diego:Libra. (ISSN: 0001-8449)

ASCHER, F. (2004). Los nuevos principios del urbanismo. Madrid: Alianza.

AUGE. M. (2006). Los no lugares; Espacios del anonimato. Una antropología de la sobremodernidad. Barcelona: Gedisa.

BAUDRILLARD, J. (1998). The Consumer Society. London: Sage Publications.

BAUMAN, Z. (2000). Trabajo, consumismo y nuevos pobres. Barcelona: Gedisa.

BELI, D. (2006). Las contradicciones culturales del capitalismo. Madrid: Alianza.

BORJA, J. (2003). La ciudad conquistada. Madrid: Alianza.

BORJA, J., y MUXI, Z. (2000). El espacio público: ciudad y ciudadanía. Barcelona: Electa.

BORJA, J. Ciutat real, ciutat ideal. Significat i funció a l'espai urbà modern, "Urbanitats" núm. 7, Centro de Cultura Contemporánea de Barcelona, Barcelona 1998

CÁCERES, G., SABATINI, F., SALCEDO, R., BLONDA, L. (2006). Malls en Santiago: luces y claroscuros. $A R Q 062$ (marzo), 48-53.

CÁCERES, G., SABATINI F., SALCEDO R. y Blonda L. (2006). Los centros comerciales en Santiago de Chile: luces y claroscuros. ARQ 062 (marzo), 48-53. (ISSN: 0717-6996)

CASTELLS, M. (2008). The New Public Sphere: Global Civil Society, Communication Networks, and Global Governance. The Annals of the American Academy of Political and Social Science, Vol.616, n.1. 78-93. 
CHOAY, F. (1997). The Rule and the Model: On the Theory of Architecture and Urbanism. MA, USA: MIT Press.

CHUNG, $\mathrm{K}$ et al. Xxxxxxxx, 2001

CRAWFORD, M. (1999). Everyday Urbanism: Michigan Debates on Urbanism I. Michigan: University of Michigan

De Solà-Morales, M. Espacios públicos espacios colectivos. En: La Vanguardia, Barcelona, 12 de mayo de 1992.

Delgado, M. (2007). Sociedades movedizas. Barcelona: Anagrama.

Delgado, M. (1999). El animal público. Barcelona, España: Anagrama.

Dupuy, G. (1998). El urbanismo de redes. Teorías y métodos. Madrid, España: Oikos-Tau.

FEINBERG, R., SHEFFLER, B., MEOLI J. y RUMMEL A. (1989). There's something social happening at the mall. Journal of Business and Psychology 4 (49-63). US: Heilderberg, Springer. (ISSN: 0889-3268)

GRUEN, V. (1964). The Heart of Our Cities: The Urban Crisis, Diagnosis and Cure. New York: Simon And Schuster.

GRUEN, V., SMITH, L. (1960). Shopping towns USA: The planning of shopping centers. New York: Reinhold.

HABERMAS, J. (2006). The Structural Transformation of the Public Sphere. Cambridge MA: MIT Press.

HALL, P. (1996). Ciudades del mañana. Historia del urbanismo en el siglo XXI. Barcelona: Ed. Del Serbal.

HARVDEY, D. (2004). La condición de la posmodernidad. Investigación sobre los orígenes del cambio cultural. Buenos Aires: Amorrortu.

HAYTKO, D. y BAKER, J. (2004). It's all at the mall: Exploringadolescent girls' experiences. Journal of Retailing 80 (Eisevier) 67-83. (ISSN: 0022-4359)

KOOLHAAS, R. (2000). Mutations. New York, USA: Actar

KOOLHAAS, R. (2006). La ciudad genérica. Barcelona: Gustavo Gili

KOZINETS, ROBERT V., SHERRY, J. Jr., STORM D., DUHACHEK, A.,NUTTAVUTHISIT, K. y SEBERRYSPENCE, B. (2004). Ludic agency and retail spectacle. Journal of Consumer Research 31 (Chicago) University of Chicago Press, 658-672. (ISSN: 0093- 5301)

LEFEBVRE, H. (2000). The Production of Space. MA: Blackwell.

LIPOVETSKY, G. (2006). Los tiempos hipermodernos, Barcelona,: Anagrama.

LIPOVETSKY, G. (2007). La felicidad paradójica. Ensayo sobre la sociedad de hiperconsumo. Barcelona: Anagrama.

LÓPEZ LEVI, L. (1999). Centros comerciales. Espacios que navegan entre la realidad y la ficción. México: Nuestro Tiempo.

LULLE, T., y PAQUETTE, C. (2007). Los grandes centros comerciales y la planificación urbana. Un análisis comparativo de dos metrópolis latinoamericanas. Revista de Estudios demográficos y urbanos, Vol.22, n.2, 337-361.

MARRERO, I. (2008). La producción del espacio público. D’Antropologia I Investigació Social, n.1, 74-90.

Moulian, T. (1999). El consumo me consume. Santiago, Chile: LOM Ediciones.

MUNICIPIO DE QUITO. Quito y su Área Metropolitana: Plan Director de Quito 1973 - 1993.

- (1980) Plan Quito. Quito, Ecuador.

- (1990) Plan de Estructura Urbana de Quito. Quito, Ecuador.

- (2001) Plan General de Desarrollo Territorial 2000 - 2020. Quito, Ecuador.

- (2012) Plan Metropolitano de Ordenamiento Territorial 2012 - 2022. Quito, Ecuador.

- (2015) Plan de Desarrollo y de Ordenamiento Territorial. Quito, Ecuador.

ROSSI, A. (2007). La arquitectura de la ciudad. Barcelona: Gustavo Gili.

SALCEDO, R. (2003). Lo local, lo global y el mall: la lógica de la exclusión y la interdependencia. Revista de Geografía, Norte Grande, n.30, 103-115.

SANDICKI, O. y HOLT, D. (1998). Malling society: Mall consumption practices and the future of public space. ServiceScapes: The concept of place in contemporary markets, Chicago: NTC Business Books. 305-336. (ISBN: 0844230057)

SARIO, B. (2009). La ciudad Vista: Mercancías y cultura urbana. Buenos Aires: Ed. Siglo XXI

SOJA, E. (2000). Third space. Journeys to Los Angeles and other real-and-imagined places. MA, USA: Ed. Blackwell.

STILLERMAN, J. (2006). The politics of space and culture in Santiago Chile's street markets, Qualitative Sociology, Vol.29, n.4. 507-530.

STILLERMAN, J. (2006b). Private, parochial, and public realms in Santiago, Chile's retail sector. City \& Community, Vol.5, n.3. (Santiago) 293-317.

STILLERMAN, J., SALCEDO, R. (2010). Es mucho más que comprar... Discursos y practicas espaciales cotidianas en Malls de Santiago. Estudios Avanzados, Vol., n.13 (Santiago) 79-103.

URTEAGA, M., Y CORNEJO I. (1995).La privatización afectiva de los espacios comerciales por las y los 
jóvenes. Ciudades 27 (Puebla) 24-28. (ISSN: 0187- 8611)

ENTURli, R., ScOTT-BROWN, D., IZENOUR, S. (2008). Aprendiendo de las Vegas. El simbolismo olvidado de la forma arquitectónica. Barcelona: Gustavo Gili.

SECCHI, B. (2013). La ciudad de los ricos y la ciudad de los pobres. Madrid: Catarata

SORKIN, M. (2004). Variaciones sobre un parque temático: la nueva ciudad americana y el fin del espacio público. Barcelona: Gustavo Gili

WALL, A. (2005). Victor Gruen From Urban Shop To New City. New York: Acta

$<<$ Fuentes electrónicas >>

Borja, J. (2002). La ciudad del deseo. En: Quaderns díarquitetura i urbanisme $\mathrm{N}^{\circ}$ 2002, p. 2: https://dialnet.unirioja.es/ejemplar/208970

Delgado, M. y Malet, D. (2013). El Espacio Público como Ideología. En: URBANDOCS. Fórum Español para la Prevención y la Seguridad Urbana http://www.fepsu.es/docs/urbandocs/URBANDOC1.pdf

PERALTA, E., y MOYA, R. (2008). Desarrollo del sector, una mirada por época. http://www.ekosnegocios.com/Inmobiliario/Articulos/1.pdf 